\title{
Involvement of Cyclin Dependent Kinase 5 in M4 Muscarinic Acetylcholine Receptor-Mediated Cholinergic Transmission within the Mouse Dorsal Striatum
}

\section{Hu Zhou}

Beijing Institute of Pharmacology and Toxicology: Academy of Military Medical Sciences Institute of Pharmacology and Toxicology

\section{Huaxiang Shi}

Beijing Institute of Pharmacology and Toxicology: Academy of Military Medical Sciences Institute of Pharmacology and Toxicology

\section{Xing Li}

Beijing Institute of Pharmacology and Toxicology: Academy of Military Medical Sciences Institute of Pharmacology and Toxicology

\section{Jingxin Zhang}

Beijing Institute of Pharmacology and Toxicology: Academy of Military Medical Sciences Institute of Pharmacology and Toxicology

\section{Xin Sui}

Beijing Institute of Pharmacology and Toxicology: Academy of Military Medical Sciences Institute of Pharmacology and Toxicology

\section{Zhe Zhao}

Beijing Institute of Basic Medical Sciences

\section{Zhiyong Nie}

Beijing Institute of Pharmacology and Toxicology: Academy of Military Medical Sciences Institute of Pharmacology and Toxicology

\section{Yongan Wang}

Beijing Institute of Pharmacology and Toxicology: Academy of Military Medical Sciences Institute of Pharmacology and Toxicology

Jin Li

Beijing Institute of Pharmacology and Toxicology: Academy of Military Medical Sciences Institute of Pharmacology and Toxicology

\section{Liyun Wang ( $\square$ lylywang1103@163.com )}

Beijing Institute of Pharmacology and Toxicology: Academy of Military Medical Sciences Institute of Pharmacology and Toxicology https://orcid.org/0000-0002-5253-7091 
Research article

Keywords: Parkinson's disease, basal ganglia, medium spiny neurons, motor symptoms, muscarinic receptors, striatum.

Posted Date: March 13th, 2021

DOl: https://doi.org/10.21203/rs.3.rs-290339/v1

License: (c) (i) This work is licensed under a Creative Commons Attribution 4.0 International License. Read Full License 


\section{Abstract}

Background: An imbalance between dopamine (DA) and acetylcholine (ACh) within the striatum has reemerged as key to the pathophysiology of the neurodegenerative disorder, Parkinson's disease (PD). $M_{4}$ is a prominent muscarinic $A C h$ receptor subtype in the striatum and we have previously reported that $\mathrm{M}_{4}$ controls cyclin-dependent kinase 5 (Cdk5) / dopamine- and cAMP-regulated phosphoprotein of $\mathrm{Mr} 32 \mathrm{kDa}$ (DARPP-32) activity in cultured medium spiny neurons (MSNs). However, the mechanism of this control remains unclear.

Methods: Genetic, electrophysiological, and immunohistochemical approaches were used in conjunction with pharmacological methods to study isolated $\mathrm{M}_{4}$-deleted $\mathrm{MSNs}\left(\mathrm{M}_{4}-\mathrm{KD} \mathrm{MSNs}\right)$ and a dorsomedial striatum (DMS) $\mathrm{M}_{4}$ knockout mouse model. We examined the role of Cdk5 in $\mathrm{M}_{4}$-mediated neural cholinergic transmission and related behavior.

Results: Oxotremorine $\mathrm{M}$, a nonselective mAchR agonist, promoted Cdk5/P35 signaling activity in DSM MSNs both in vivo and in vitro. Either pharmacological inhibition or genetic knockdown of $\mathrm{M}_{4}$ decreased the amount of Cdk5 and DARPP-32 phosphorylation at Thr75 in dopamine 1 receptor-expressing MSNs. Furthermore, whole-cell patch-clamp recording confirmed Cdk5 is necessary for $\mathrm{M}_{4}$-mediated cholinergic inhibition of excitatory synaptic transmission in MSNs in vivo and in vitro. Concomitantly, deletion of $\mathrm{M}_{4}$ activity in the DMS caused Oxotremorine M-induced Cdk5 signaling and glutamatergic synaptic input to be altered in parallel with behavioral responses.

Conclusions: We characterized a novel regulatory mechanism of Cdk5/DARPP-32 involved in $\mathrm{M}_{4^{-}}$ mediated cholinergic regulation on striatonigral neurons and on motor behavior. The findings indicate that inhibition of $\mathrm{M}_{4} \mathrm{mAChR}$ could be a novel approach to correct the pathological conditions of PD.

\section{Background}

Parkinson's disease (PD) is a neurodegenerative disorder caused by the loss of nigral dopaminergic neurons innervating the striatum [1]. This in turn results in an imbalance between dopaminergic and cholinergic systems [2,3]. The striatum, the main input nucleus of the basal ganglia, is critical for the integration of multiple cortical and subcortical inputs underlying action control and voluntary movements [4-6]. The striatum largely comprises GABAergic projection neurons known as medium spiny neurons (MSNs) that are generally subdivided into two efferent pathways: dopamine 1 receptor $\left(D_{1}\right)$-expressing MSNs ( $\left.D_{1}-M S N s\right)$, which give rise to the striatonigral or direct pathway, and dopamine 2 receptor $\left(D_{2}\right)$ expressing MSNs ( $\mathrm{D}_{2}-\mathrm{MSNs}$ ), which give rise to the striatopallidal or indirect pathway [7]. Balanced activation of these two pathways is necessary for normal motor and non-motor functions $[8,9]$.

Acetylcholine (ACh) regulates many key functions by activating cell surface receptors referred to as muscarinic ACh receptors ( $m A C h R s ; M_{1}-M_{5}$ ) [10]. mAChRs are densely expressed on striatal MSNs, and $M_{4}$ receptors are primarily expressed on striatonigral $D_{1}-M S N s[11,12]$. Striatal mAChRs inhibit 
dopaminergic signaling, and also differentially regulate dopamine- and cAMP-regulated phosphoprotein of Mr $32 \mathrm{kDa}$ (DARPP-32) signaling in striatonigral and striatopallidal neurons [13, 14]. DARPP-32 is expressed in D1-MSNs and contains several sites for regulatory phosphorylation, including Thr34 and Thr75 [15]. Besides phosphorylation at Thr34 by dopamine/PKA, DARPP-32 is also phosphorylated by cyclin-dependent kinase 5 (Cdk5) at Thr75, converting DARPP-32 into a PKA inhibitor [16]. We have previously reported that $\mathrm{M}_{4}$ regulates the phosphorylation of DARPP-32 at Thr75 in cultured MSNs [17]. These findings suggest that cyclin-dependent kinase 5 (Cdk5)-specific phosphorylation associated with DARPP-32 seems to be controlled by $\mathrm{M}_{4}$ stimulation. However, the mechanisms by which Cdk 5 acts in $\mathrm{M}_{4}$-mediated neural cholinergic transmission and related behavioral responses are unclear.

The dorsomedial striatum (DMS) is thought to be involved in early stages of motor processing and thus alterations in DMS signaling are likely to yield global changes in motor behavior $[18,19]$. The information conveyed to this subcortical structure through glutamatergic projections from the cerebral cortex and thalamus is processed by several striatal neuromodulatory systems, including the cholinergic system [20]. In this study, we used lentiviral-mediated $M_{4}$-shRNA transduction to knockdown the $M_{4}$ gene in isolated MSNs in vitro. We also used lentiviral CRISPR-Cas9 technology to delete $M_{4}$ in the DMS of mice in vivo. DARPP-32 also acts as an integrator of dopaminergic and glutamatergic inputs [21]; Therefore, using pharmacological and electrophysiological approaches, we analyzed Cdk5 activity and the glutamatergic input to striatonigral MSNs in vitro and in vivo. In parallel with biochemical changes, we also studied behavioral responses in the $\mathrm{DMS} \mathrm{M}_{4}$ knockout (DMS-M $\left.\mathrm{M}_{4}-\mathrm{KD}\right)$ mouse. It is important to understand the functional role of $\mathrm{M}_{4}$ modulation of region-specific striatal neural circuitry in neurodegenerative disorders such as Parkinson's disease.

\section{Methods}

\section{Animals and reagents}

Experiments were performed with 8-week-old C57BL/6J mice (RRID: MGI: 5657312) and 12-hour-old Sprague-Dawley rats (RRID: MGI: 5651135) supplied by the Animal Center of the Academy of Military Medical Science (Beijing, China). C57BL/6J mice were group-housed in a temperature-controlled environment $\left(22 \pm 2^{\circ} \mathrm{C}\right)$ with a $12 / 12-\mathrm{h}$ light/dark cycle and access to food and water ad libitum. All mice were group-housed for 3 days prior to use and were handled daily throughout the experiment to minimize the effects of handling stress. All tests were performed and recorded between 9:00 and 15:00 during the lights-on cycle. Animal experiments (Ethics approval No. LACUC-DWZX-2020-517) were approved by the Beijing Local Committee on Animal Care and Use and were performed according to the Guide for the Care and Use of Experimental Animals produced by the Beijing Local Committee and the National Institutes of Health Guide for the Care and Use of Laboratory Animals (NIH publication No. 85-23, revised 1985). Efforts were made to minimize the number of animals used for each experiment. 
The following reagents were used. Oxotremorine M (0xo-M, Cat. \#0100) was purchased from SigmaAldrich (St. Louis, MO, USA). Roscovitine (ROSC, Cat. \#T6259) was purchased from Target Mol (Shanghai, China). Muscarinic toxin 3 (MT3, Cat. \#4410-s) and muscarinic toxin 7 (MT7, Cat. \#4340-s) were obtained from the Peptide Institute (Tokyo, Japan). All reagents were dissolved or diluted in normal saline as vehicle and the solutions were adjusted to a $\mathrm{pH}$ range of 6.5 to 7.0.

\section{Primary cultures of MSNs}

According to methods described previously [17], primary MSN cultures were prepared from neonatal (12h-old) Sprague-Dawley rats. In brief, the striatum was dissected in ice-cold PBS (135 mM NaCl, $2.7 \mathrm{mM}$ $\mathrm{KCl}, 1.5 \mathrm{mM} \mathrm{KH}_{2} \mathrm{PO}_{4}$, and $8 \mathrm{mM} \mathrm{K}_{2} \mathrm{HPO}_{4}, \mathrm{pH} 7.2$ ). The tissue was then digested in $0.25 \%$ trypsin for 30 min at $37^{\circ} \mathrm{C}$ until completely triturated. Next, the cells were suspended in neurobasal medium (Gibco, Thermo Scientific, MA, USA, Cat. \#A3582901) containing 1\% L-glutamine (Gibco, Thermo Scientific, Cat. \#35050061) and 2\% B-27 serum-free supplement (Gibco, Thermo Scientific, Cat. \#17504044) and plated at equal density in 15-mm-diameter dishes (NEST Biotechnology Co. Ltd., CA, USA, Cat. \#801002) precoated with $0.1 \mathrm{mg} / \mathrm{mL}$ poly-D-lysine (Sigma-Aldrich). The cells were incubated at $37^{\circ} \mathrm{C}$ in a $5 \% \mathrm{CO}_{2}$ atmosphere.

\section{Lentiviral $\mathrm{M}_{4}$-shRNA transduction and knockdown of $\mathrm{M}_{4}$ in isolated MSNs}

A pGMLV-SC5 lentivirus shRNA expression system encoding a cholinergic receptor, muscarinic 4 shRNA (Chrm4-shRNA) was constructed as previously described [17]. The sequence inserted into PGMLV-hU6MCS-CMV-ZsGreen1-PGK-Puro-WPRE to generate Chrm4-shRNA was 5'GATCCGCAAAGTGACTCGGACAATCTTTCAA GAGAAGATTGTCCGAGTCACTTTGTTTTTTTG-3'. The shRNA sequence 5'-TTC TCCGAACGTGTCACGT-3' was used as a negative control (NC). Primary MSNs were plated onto $0.1 \%$ polyethylene poly-L-lysine-coated 15 -mm-diameter dishes or 6-well plates (NEST Biotechnology Co. Ltd., Cat. \#703001). After culture for 24 h, cells were transduced with Chrm4-shRNA or NC shRNA lentiviral vectors and incubated at $37^{\circ} \mathrm{C}$ in a $5 \% \mathrm{CO}_{2}$ atmosphere for $96 \mathrm{~h}$. Cells transduced with Chrm4-shRNA are referred to as $\mathrm{M}_{4}-$ knockdown $\left(\mathrm{M}_{4}-\mathrm{KD}\right) \mathrm{MSNs}$.

\section{Knockout of the $\mathrm{M}_{4}$ gene within the DMS by lentiviral delivery of CRISPR/Cas9}

Three single-guide RNAs (sgRNAs) targeting the $\mathrm{M}_{4}$ gene were designed and assessed for off-target activities using MIT CRISPR Design. The sgRNAs were synthesized by Jikai Gene Company (Shanghai, China). Each sgRNA was cloned into a lentiviral (LV)-sgRNA-CAS9 vector containing a U6 promoter multicloning site and P2A promoter-driven enhanced green fluorescent protein (eGFP) and then packaged 
into the GV393 vector. A vector expressing a sgRNA targeting a non-specific sequence (5'CGCTTCCGCGGCCCGTTCAA-3') was used as a negative control (NC). The specific sequence used for targeted editing of $\mathrm{M}_{4}$ was (5'-CACCGTGCCA GCATCGCTCGTAACC-3') (for cloning details, see Additional file: supplementary cloning construction). C57BL/6J mice were anesthetized with $5 \%$ chloral hydrate (5 $\mathrm{mL} / \mathrm{kg}$, i.p.) then mounted on a stereotaxic apparatus (Kopf Instruments, Beijing, China). We injected $3 \mu \mathrm{L}$ GV393 LV/Cas9-sgRNA-eGFP containing the targeting or NC sgRNA into the DMS at three sites within the DMS (site 1: $+1.0 \mathrm{~mm} \mathrm{AP}, \pm 2.0 \mathrm{~mm} \mathrm{ML},-3.5 \mathrm{~mm} \mathrm{DV}$; site 2: $+1.2 \mathrm{~mm} \mathrm{AP}, \pm 2.1 \mathrm{~mm} \mathrm{ML},-3.5 \mathrm{~mm} \mathrm{DV}$; and site 3: $+0.7 \mathrm{~mm} \mathrm{AP}, \pm 2.2 \mathrm{~mm} \mathrm{ML},-3.5 \mathrm{~mm} \mathrm{DV}$; according to the stereotaxic mouse atlas of Paxinos and Franklin, 2001). After injection, needles were left in place for $5 \mathrm{~min}$ to allow the solutions to fully diffuse.

\section{Microinjection and drug treatment}

Oxo-M was dissolved in vehicle and the final dose used was $0.1 \mu \mathrm{M}$. Mice received intracerebroventricular (i.c.v) injection of Oxo-M $(2.0 \mu \mathrm{L})$ or vehicle $(2.0 \mu \mathrm{L})$ at the following coordinates: $+1.0 \mathrm{~mm} \mathrm{AP}, \pm 0.2 \mathrm{~mm}$ $\mathrm{ML},-2.5 \mathrm{~mm}$ DV. The solutions were injected bilaterally through a microinjection needle (30 gauge) that extended $1 \mathrm{~mm}$ beyond the tip of the guide cannula. Each microinjection needle was attached to a $10-\mu \mathrm{L}$ Hamilton microsyringe through polyethylene tubing (PE-10). Infusions were controlled by an infusion pump (Model Bi2000e Insight Equipment, Sao Paulo, Brazil), programmed to deliver solution at a constant speed of $0.5 \mu \mathrm{L}$ per min. The microinjection needle was kept in place for an additional minute to allow for drug diffusion. The mice were allowed to move freely during drug administration.

\section{Behavioral tests}

Mice were screened 3 days before lentivirus or drug injection, and those with abnormal motor behavior were excluded. Behavioral tests were performed 14 days after lentivirus injection. Mice were transferred to a behavioral testing room $\left(22 \pm 1^{\circ} \mathrm{C}\right)$ and habituated for at least $5 \mathrm{~min}$ before behavioral testing. All behavioral experiments were performed at fixed times (autonomic movement test: 9:00-12:00; rotarod and forced swim test: 12:00-14:00). The testing apparatus was cleaned with a hypochlorous acid solution.

\section{Locomotor activity measurements}

Mice were individually transferred from their home cage to a plastic open field apparatus $(60 \mathrm{~cm} \times 60 \mathrm{~cm}$ $\times 60 \mathrm{~cm}$; Xingruan Information Technology Co. Ltd., Beijing, China). The apparatus was virtually divided into peripheral, intermediate, and central zones. The test was started by placing the animal in the center of the open field illuminated by a dim light $(5 \mathrm{~lx})$. Each mouse was placed in the locomotor activity box for $60 \mathrm{~min}$ and was recorded by a video camera. The total distance and the distance traveled in the central zone (referred to hereafter as central distance) was recorded and analyzed by ANY-Maze automated video tracking software (Stoelting Co., Wood Dale, IL, USA; RRID: SCR_014289). 


\section{Rotarod test}

The rotarod system (Xingruan Information Technology Co. Ltd, China) for assessing locomotor skills measures the time that an animal maintains balance on a moving rod. Animals were first conditioned on a stationary rod for $30 \mathrm{~s}$ and during this time any animal that fell was placed back on the rotarod. Animals were next conditioned at a constant speed of $5 \mathrm{rpm}$ for a period of $5 \mathrm{~min}$. Twenty-four hours after conditioning, animals were placed on the rod and timed for $30 \mathrm{~min}$ to assess their locomotor skill. The rod speed started at $5 \mathrm{rpm}$ and was increased at $0.1 \mathrm{rev} / \mathrm{s}$; the time before falling off the rod (fall off duration) was recorded by ANY-Maze automated video tracking software (Stoelting Co. Ltd., Sheboygan, IL, USA).

\section{Forced swimming test}

The test procedure was previously standardized and validated [22]. Mice were individually forced to swim in an open cylindrical container (diameter $10 \mathrm{~cm}$, height $25 \mathrm{~cm}$ ) containing $19 \mathrm{~cm}$ of water (depth) at $25 \pm$ $1^{\circ} \mathrm{C}$. Each mouse was considered to be immobile when it ceased struggling and remained floating motionless in the water. The total duration of immobility was recorded during a 10-min period by ANYMaze automated video tracking software (Stoelting Co. Ltd, China).

\section{Immunocytochemistry and confocal microscopy analysis}

For immunocytochemistry, cells were fixed in methanol for $20 \mathrm{~min}$ and blocked with $5 \%$ BSA (ZSGB-Bio, Wuhan, China) in PBS for $1 \mathrm{~h}$, then incubated with primary antibodies overnight at $4^{\circ} \mathrm{C}$. The cells were then washed before incubation with the corresponding secondary antibody for $1 \mathrm{~h}$ at room temperature.

For immunohistochemistry, tissues were dissected and postfixed overnight at $4^{\circ} \mathrm{C}$ in $4 \%$ paraformaldehyde and then cryoprotected with $30 \%$ sucrose in $0.1 \mathrm{M}$ PBS for 2 days. Sections were cut at $30 \mu \mathrm{m}$ on a cryostat microtome (CM1950, Leica, Wetzlar, Germany). Free-floating sections were permeabilized with $0.3 \%$ Triton X-100 in PBS for 30 min at room temperature. After blocking with $10 \%$ normal goat serum for $2 \mathrm{~h}$, sections were incubated with primary antibodies overnight at $4^{\circ} \mathrm{C}$. Sections were then incubated with secondary antibodies for $2 \mathrm{~h}$ at room temperature.

The primary and secondary antibodies are shown in Additional file: supplementary Table 1. The nuclear layers were stained with DAPI (Sigma-Aldrich). Images were obtained with a laser confocal microscope (LSM 8000, Carl Zeiss, Oberkochen, Germany). ImageJ imaging software (National Institutes of Health, MD, USA) was used to quantify the fluorescence intensity.

\section{Western blotting}

Primary cell cultures or dorsal striatum tissue were lysed in RIPA buffer (50 mM Tris, $150 \mathrm{mM} \mathrm{NaCl}, 5 \mathrm{mM}$ $\mathrm{NaF}, 0.2 \%$ SDS, and $1 \% \mathrm{NP}-40, \mathrm{pH} 8.0$ ) containing a mix of protease and phosphatase inhibitors (Google 
Biological Technology Co., Ltd., Wuhan, China) before being centrifuged at $4^{\circ} \mathrm{C}, 12,000 \times \mathrm{g}$, for $30 \mathrm{~min}$. The supernatants were collected, and protein concentration measured using a commercial BCA kit (Google Biological Technology Co., Ltd.). Equal amounts of protein were separated on 10\% SDS-PAGE gradient gels, transferred to nitrocellulose membranes, and incubated with primary antibodies diluted in TBST (150 mM NaCl, $40 \mathrm{mM}$ Tris- $\mathrm{HCl}, \mathrm{pH} 7.4,0.1 \%$ Tween-20) overnight at $4^{\circ} \mathrm{C}$. After washing, membranes were incubated with secondary antibodies coupled to horseradish peroxidase. The primary and secondary antibodies are shown in Additional file: supplementary Table 2. Immunocomplexes were detected by chemiluminescence (ECL, Pierce, USA), imaged using an imaging instrument (GENE Co. Ltd., Beijing, China) and analyzed using Image J. Analyses were performed in duplicate and the mean value was calculated.

\section{Whole-cell patch clamp electrophysiology in the DMS.}

Mice were anesthetized by injection with pentobarbital sodium (60 mg/ $\mathrm{kg}$, i.p.), then decapitated and the brains removed. Coronal slices ( $300 \mu \mathrm{m}$ thick) containing the striatum (0.2-1.3 mm posterior to bregma) were prepared in ice-cold ACSF (as follows: $124 \mathrm{mM} \mathrm{NaCl}, 2.8 \mathrm{mM} \mathrm{KCl}, 1.25 \mathrm{mM} \mathrm{NaH}_{2} \mathrm{PO}_{4}, 2 \mathrm{mM} \mathrm{CaCl}_{2}$, $1.25 \mathrm{mM} \mathrm{MgSO}_{4}, 26 \mathrm{mM} \mathrm{NaHCO}_{3}, 10 \mathrm{mM}$ glucose, $\mathrm{pH} 7.5$, bubbled with $95 \% \mathrm{O}_{2} / 5 \% \mathrm{CO}_{2}$ ) using a vibrating tissue slicer (MA752, Campden Instruments, USA) as previously described [23]. Slices were submerged for $30 \mathrm{~min}$ at $32^{\circ} \mathrm{C}$ in protective media containing $2.5 \mathrm{mM} \mathrm{KCl}, 1.2 \mathrm{mM} \mathrm{NaH}_{2} \mathrm{PO}_{4}, 30 \mathrm{mM}$ $\mathrm{NaHCO}_{3}, 20 \mathrm{mM}$ Hepes, $25 \mathrm{mM}$ D-glucose, $5 \mathrm{mM}$ sodium ascorbate, $2 \mathrm{mM}$ thiourea, $3 \mathrm{mM}$ sodium pyruvate, $10 \mathrm{mM} \mathrm{MgSO}_{4}, 0.5 \mathrm{mM} \mathrm{CaCl}_{2}(\mathrm{pH} \mathrm{7.3})$ at 295-300 mOsm/L. Following this recovery period, slices were transferred to ACSF containing $126 \mathrm{mM} \mathrm{NaCl}, 2.5 \mathrm{mM} \mathrm{KCl}, 26.2 \mathrm{mM} \mathrm{NaHCO}_{3}, 1.25 \mathrm{mM}$ $\mathrm{NaH}_{2} \mathrm{PO}_{4}, 2 \mathrm{mM} \mathrm{CaCl}_{2}, 1.5 \mathrm{mM} \mathrm{MgSO}_{4}, 10 \mathrm{mM}$ D-glucose and $5 \mathrm{mM}$ sodium ascorbate.

Patch pipets were prepared from borosilicate glass (Sutter Instrument Company, Novato, CA, USA) using a P-97 Flaming/Brown micropipette puller (Sutter Instrument) and had resistance of 6-8 $\mathrm{M} \Omega$ when filled with the following intracellular solution: $130 \mathrm{mM} \mathrm{CsCl}, 10 \mathrm{mM} \mathrm{NaCl}, 0.25 \mathrm{mM} \mathrm{CaCl}_{2}, 2 \mathrm{mM} \mathrm{MgCl}_{2}, 5 \mathrm{mM}$ EGTA, $10 \mathrm{mM}$ Hepes, $10 \mathrm{mM}$ glucose, $2 \mathrm{mM} \mathrm{Mg-ATP}$, and $0.3 \mathrm{mM} \mathrm{Na} \mathrm{N}_{2}$-GTP. The $\mathrm{pH}$ of the pipette solution was adjusted to 7.3 with $1 \mathrm{mM} \mathrm{CsOH}$ and osmolarity was adjusted to $285-290 \mathrm{mOsm} / \mathrm{L}$. A low-power objective (4x) was used to identify the striatum and a $40 \times$ water immersion objective (NIR Apo, Nikon, Tokyo, Japan), coupled with infrared differential interference contrast microscopy and a charge coupled device camera, was used to visualize individual neurons. Cells in the dorsolateral striatum up to approximately $50 \mu \mathrm{m}$ beneath the slice surface were patched and monitored. Recordings in normal current-clamp or voltage-clamp mode were acquired at room temperature using the Digidata $1440 \mathrm{~A}$ interface (Molecular Devices, Sunnyvale, CA, USA) with an Axon 200B amplifier (Molecular Devices) and Clampex 10.2 software (Molecular Devices). After formation of a tight seal (>1 G $\Omega$ ), fast and slow capacitance compensation was performed. During the whole-cell recording, series resistance was compensated (80\%-90\%) and monitored periodically. Neurons were excluded from the analysis when their series resistance was above $50 \mathrm{G} \Omega$ or changed by more than $25 \%$ during the experiment. Data were 
filtered at $2 \mathrm{kHz}$ and acquired at a sampling rate of $10 \mathrm{kHz}$. MSNs were identified by previously determined membrane characteristics and firing patterns [24].

For miniature excitatory postsynaptic current (mEPSC) recordings, oxygenated ACSF containing both the GABA receptor antagonist bicuculline $(10 \mu \mathrm{M}$; Sigma) and the voltage-gated sodium channel blocker tetrodotoxin (TTX; $1 \mu \mathrm{M}$; Abcam Biochemicals, UK) was applied to the bath to abolish inhibitory postsynaptic current events and action potentials, respectively. Slices were perfused with this solution at $25^{\circ} \mathrm{C}$ for at least $15 \mathrm{~min}$ following establishment of electrical access. Access resistances were $<15 \mathrm{M} \Omega$. mEPSCs were recorded from MSNs held at $70 \mathrm{mV}$ in gap-free mode. After $5 \mathrm{~min}$ of stable baseline recordings, Oxo-M was bath applied to slices for 5 min and recording performed for at least $3 \mathrm{~min}$.

\section{Whole-cell patch clamp electrophysiology in primary MSN cultures}

Whole-cell patch clamp recordings were performed on primary MSNs from the striatum of newborn Sprague-Dawley rats cultured for 14 to 16 days in vitro. Borosilicate patch pipettes (6-8 $\mathrm{M} \Omega$ ) were filled with an internal solution containing the following: $130 \mathrm{mM} \mathrm{CsCl}, 10 \mathrm{mM} \mathrm{NaCl}, 0.25 \mathrm{mM} \mathrm{CaCl}_{2}, 2 \mathrm{mM}$ $\mathrm{MgCl}_{2}, 5 \mathrm{mM}$ EGTA, $10 \mathrm{mM}$ Hepes, $10 \mathrm{mM}$ glucose, $2 \mathrm{mM} \mathrm{Mg-ATP,} 0.3 \mathrm{mM} \mathrm{Na}$-GTP (pH 7.35). Cultures were continuously superfused with an external solution: $100 \mathrm{mM} \mathrm{NaCl}, 26 \mathrm{mM} \mathrm{NaHCO}_{3}, 2.5 \mathrm{mM} \mathrm{KCl}, 11$ $\mathrm{mM}$ glucose, $2.5 \mathrm{mM} \mathrm{CaCl}_{2}, 1.3 \mathrm{mM} \mathrm{MgSO}_{4}, 1.0 \mathrm{mM} \mathrm{NaH}_{2} \mathrm{PO}_{4}$. For mEPSC recordings, the bath solution contained TTX $(1 \mu \mathrm{M})$ and bicuculline $(10 \mu \mathrm{M})$. Cells were held at $60 \mathrm{mV}$. The time course of the experiments, data collection and analysis were the same as for slice electrophysiology.

\section{Experimental overview}

For characterization of $\mathrm{M}_{4}$-mediated cholinergic modulation of behavior, we directly injected Oxo-M (0.1 $\mu \mathrm{M}, 2 \mu \mathrm{L}$ ) into the lateral ventricle of wild-type (WT), NC and DMS-M $\mathrm{M}_{4}-\mathrm{KD}$ mice once daily for 3 consecutive days. A control group received daily saline injections. After Oxo-M injection, one set of mice was immediately used for evaluation of behavioral responses. Another set of mice was killed by decapitation $2 \mathrm{~h}$ after the final Oxo-M injection to assess biochemical changes in the DMS using immunohistochemistry, confocal microscopy and western blot analyses. For characterization of $\mathrm{M}_{4^{-}}$ mediated cholinergic inhibition of neuronal electrophysiological activity, tissues from the DMS were dissected for whole-cell patch clamp electrophysiology analyses.

\section{Data analysis}

For behavioral experiments and biochemistry assays, including immunocytochemistry and western blotting, statistical analysis was performed by one-way ANOVA or two-way ANOVA (with or without repeated measures) followed by Tukey's multiple comparisons test using GraphPad Prism 7.0 (GraphPad, San Diego, CA). For electrophysiology, statistical analysis was performed using Clampex 10.2 software (Molecular Devices). The two-sample Kolmogorov-Smirnov test was used to compare the cumulative distributions of frequency of the two groups. Data are expressed as the mean \pm S.E.M. " $n=8$ " is the 
number of animals used, " $n=10$ " is the total number of ROIs in immunocytochemistry staining and patch clamp electrophysiology (cells or tissue sections), and " $n=3$ " the number of independent western blotting experiments performed, unless otherwise stated. $P$ values below 0.05 were considered significant.

\section{Results}

\section{Oxo-M activates Cdk5 resulting in DARPP-32 Thr75 phosphorylation in $\mathrm{D}_{1}-\mathrm{MSN}$ sin vitro}

We examined whether DARPP-32 Thr75 phosphorylation occurred simultaneously with Cdk5 activity in $D_{1}-M S N s$. $D_{1}-M S N s$ were characterized using specific antibodies against $D_{1}$ receptors in cultures of isolated MSNs. Figure 1a shows increased expression of Cdk5 along with an increase in DARPP-32 pThr75 immunoreactivity in $\mathrm{D}_{1}$-MSNs following treatment with the nonselective mAchR agonist, Oxo-M $(0.1 \mu \mathrm{M})$, for $15 \mathrm{~min}$. We then extracted lysates from the same MSN cultures treated with 0xo-M $(0.1,1$, $10 \mu \mathrm{M})$ for $15 \mathrm{~min}$. As shown in Fig. 1b, Oxo-M progressively increased levels of Cdk5 in a dosedependent manner. In MSNs treated with $10 \mu \mathrm{M}$ Oxo-M, the level of Cdk5 was increased by $54.36 \pm 2.52 \%$ [vs vehicle, $p<0.001, F(3,8)=11.82$ ]. Similarly, Oxo-M dose-dependently stimulated p35 and p25 expression, which is necessary for Cdk5 activation [25-27]. The amount of total p25 protein increased by 1.98-fold with $10 \mu \mathrm{M}$ Oxo-M treatment compared with vehicle treatment [vs vehicle, $p<0.001, \mathrm{~F}(3,8)=$ 67.24]. In addition, as shown in Fig. 1c, the Oxo-M-induced Cdk5 and DARPP-32 p-Thr75 immunoreactivity were significantly suppressed by pretreatment with Cdk5 inhibitor ROSC $(10 \mu \mathrm{M})$ for 10 min before treatment with Oxo-M for 15 min. Western blotting (Fig. 1d) confirmed that levels of Cdk5 and DARPP-32 p-Thr75 were concomitantly and significantly decreased in the presence of ROSC at $10 \mu \mathrm{M}$ [vs Oxo-M, Cdk5: $p<0.001, \mathrm{~F}(3,8)=13.61$; DARPP-32 p-Thr75: $p<0.01, \mathrm{~F}(3,8)=25.97$ ]. The results demonstrated that Oxo-M stimulated Cdk5 to induce intracellular DARPP-32 Thr75 phosphorylation in $\mathrm{D}_{1^{-}}$ MSNs.

\section{Blockade of $\mathrm{M}_{4}$ receptors disrupts Cdk5/DARPP-32 p-Thr75 signaling induced by 0xo-M in cultured striatal MSNs}

Immunostaining confirmed that Oxo-M $(10 \mu \mathrm{M})$ upregulated Cdk5 in the vast majority $(\geq 79.70 \pm 10.71 \%)$ of $\mathrm{M}_{4}$-positive MSNs (Additional file: Figure S1). Confocal microscopy analysis revealed Cdk5 distribution in $\mathrm{M}_{4}$-positive MSNs (Fig. 2a). We used Pearson's correlation coefficients (PCC) and Mander's colocalization coefficients (MCC) to examine the correlation between the $\mathrm{M}_{4}$ and Cdk5 fluorophores. Quantitative whole cell scanning analyzed the PCC and MCC values on the XZ, XY and ZY axes (Fig. 2b). The values for $P C C$ were: $X Z, 0.77 \pm 0.05 ; X Y, 0.96 \pm 0.09$; and $Y Z, 0.8 \pm 0.06$. The values for $M C C$ were: $X Z$, $0.95 \pm 0.02 ; X Z, 0.91 \pm 0.01 ; Y Z, 0.96 \pm 0.04$. These results indicate a high correlation between Cdk5 and $\mathrm{M}_{4}$ because the values were close to " 1 ". This indicates that Cdk5/DARPP-32 p-Thr75 is highly involved in $\mathrm{M}_{4}$-mediated cholinergic transmission at the cellular level in the striatum (summarized in Fig. 2b).

$M_{4}$ and $M_{1}$ are the dominant $m A$ chR subtypes on striatal MSNs; therefore, we then blocked $M_{4}$ and $M_{1}$ using the selective $M_{1}$ and $M_{4}$ antagonists, MT7 and MT3 (Fig. 2c), respectively. MT3 (0.1 $\left.\mu M\right)$ 
significantly reduced the stimulatory effect of Oxo-M on Cdk5 [vs Oxo-M, $p<0.01, \mathrm{~F}(3,8)=57.25]$, but MT7 $(0.1 \mu \mathrm{M})$ did not have a significant effect on Cdk5 [vs Oxo-M, $p=1.00, F(3,8)=8.48]$ (Fig. 2d). Importantly, MT3 abolished Oxo-M-induced p35 and p25 upregulation [vs Oxo-M, p35: $p<0.01, \mathrm{~F}(3,8)=$ 60.54; p25: $p<0.05, \mathrm{~F}(3,8)=7.30$ ] (Fig. 2e). We also constructed Chrm4-shRNA pGMLV-SC5 to delete the $\mathrm{M}_{4}$ gene in MSNs ( $\mathrm{M}_{4}-\mathrm{KD}$ MSNs) using lentivirus technology (Additional file: Figure $S 2$ for details). A schematic of the lentivirus PGMLV-SC5 RNA vector and the sequence for the target gene are shown in Fig. 2f. Immunocytochemical and western blot assays confirmed $M_{4}$ knockdown $96 \mathrm{~h}$ after MSNs were transduced with Chrm4-shRNA. We then examined the effect of Oxo-M (10 $\mu \mathrm{M}, 15 \mathrm{~min})$ on Cdk5/DARPP$32 \mathrm{p}$-Thr75 expression in $\mathrm{M}_{4}$-KD MSNs. There was a significant difference in Cdk5/DARPP-32 p-Thr75 expression between Chrm4-shRNA-eGFP-positive and negative shRNA-eGFP control (NC) MSNs; Oxo-M failed to induce Cdk5 and DARPP-32 p-Thr75 in KD-M 4 MSNs (Fig. 2g). Quantification showed the immunoreactivity was decreased $46.86 \pm 2.89 \%$ for Cdk5 and $58.33 \pm 7.44 \%$ for DARPP-32 p-Thr75 (vs NC: Oxo-M treatment, Cdk5: $p<0.001$; DARPP-32 p-Thr75: $p<0.001$ ) (Fig. 2i). These results demonstrated $\mathrm{M}_{4}$-specific stimulation of Cdk5/p-Thr75 DARPP-32 in $\mathrm{D}_{1}$-MSNs, as illustrated in Fig. $2 \mathrm{i}$.

\section{Cdk5 is necessary for $\mathrm{M}_{4}$-mediated cholinergic inhibition of excitatory synaptic transmission in MSNsin}

vitro

ACh potently modulates glutamate signaling in the striatum via activation of $m A C h R s$, and $M_{4}$ is preferentially expressed in $D_{1}-M S N s$ where it is clustered near axospinous glutamatergic synapses $[2,28]$. We investigated whether $\mathrm{M}_{4}$ and $\mathrm{Cdk} 5$ modulate local glutamatergic synaptic input on MSNs by recording miniature postsynaptic potential (mEPSCs), which reflect the presynaptic release of excitatory neurotransmitter vesicles. mEPSCs were recorded from primary cultured MSNs in the presence of bicuculline and TTX. Bath application of Oxo-M $(2,5,10 \mu \mathrm{M})$ evoked a rightward shift in cumulative probability of glutamate release from MSNs, indicating a concentration-dependent inhibition of excitatory synaptic transmission by Oxo-M (Fig. 3a, b). There was a $65.71 \pm 4.30 \%$ reduction in mEPSC frequency with $10 \mu \mathrm{M}$ Oxo-M compared with that with vehicle $[p<0.001, \mathrm{~F}(3,36)=51.91)]$. Considering a potential contribution of Cdk5 in cholinergic transmission, we then tested the effect of Cdk5 inhibitors on Oxo-Minduced cholinergic inhibition of glutamatergic transmission. When we coapplied ROSC $(100,300,500$ $\mu \mathrm{M})$ with Oxo-M $(10 \mu \mathrm{M})$, the inhibitory effect of Oxo-M on mEPSC frequency was partially antagonized (Fig. 3c, d), and $500 \mu \mathrm{M}$ ROSC significantly counteracted the action of Oxo-M $(10 \mu \mathrm{M})$ on mEPSC frequency; the inhibition of mEPSC frequency was decreased to $44.71 \pm 12.73 \%$ [ $v s$ Oxo-M, $p<0.05, \mathrm{~F}$ $(3,36)=4.08$, Fig. $3 \mathrm{~d}$ ]. We also performed identical studies in $\mathrm{M}_{4}-\mathrm{KD}$ MSNs (Fig. 3e). Compared with WT MSNs, Oxo-M-induced inhibition in mEPSC frequency was abolished in $\mathrm{M}_{4}-\mathrm{KD}$ MSNs (Fig. 3f). The inhibition of mEPSC frequency was decreased to $7.27 \pm 3.19 \%$ (vs WT: Oxo-M treatment, $p<0.001$, Fig. $3 g$ ). Taken together, these data indicate that $M_{4}$ mediates cholinergic inhibition at glutamate terminals and that Cdk5 plays a role in the cholinergic modulation of MSN synaptic activity.

\section{$\mathrm{M}_{4}$ deletion in the DMS alters Oxo-M-induced behavioral responses in mice}


We next tested $\mathrm{M}_{4}$ function in vivo using CRISPR-Cas9 gene targeting technology to create mice that lack functional $\mathrm{M}_{4}$ receptors in the DMS (DMS-M $\mathrm{M}_{4}-\mathrm{KD}$ ) (see Additional file: Figure S3-4 for details). We directly injected Oxo-M $\left(0.1 \mu \mathrm{M}, 2 \mu \mathrm{L}\right.$, i.c.v) into the lateral ventricle of WT and DMS-M $\mathrm{M}_{4}-\mathrm{KD}$ mice on 3 consecutive days and assessed behavioral responses to $\mathrm{mAChR}$ agonists. The experimental timeline and drug treatments are shown in Fig. 4a. Spontaneous locomotor activity was measured over a 60 min period in WT, NC and DMS-M - KD mice, there is not significant different in basal locomotion activity (Additional file: Figure S5). However, after administration of Oxo-M (total distance: $23.82 \pm 4.97 \mathrm{~m}$ ) in WT mice, compared with vehicle-treated WT mice(total distance: $63.33 \pm 5.90 \mathrm{~m}$ ), Oxo-M-treated WT mice had significantly reduced spontaneous activity [total distance: two-way ANOVA, interaction: $\mathrm{F}(1,28)=32.36, p$ $<0.001]$. The Oxo-M-induced suppression of locomotor activity was greatly attenuated in DMS-M $\mathrm{M}_{4}-\mathrm{KD}$ mice (total distance: $56.88 \pm 15.07 \mathrm{~m}$ ), and the total distance was similar to that of WT mice. These results indicated that the effect of Oxo-M on locomotion was mainly mediated through $\mathrm{M}_{4}$ in the DMS. In the rotarod test, the fall off duration was significantly increased in Oxo-M-treated mice compared with that in vehicle-treated mice [19.66 $\pm 0.51 \mathrm{~min} v s 11.00 \pm 3.24 \mathrm{~min}$; interaction: $\mathrm{F}(1,28)=5.5, p=0.0263]$. The effect of Oxo-M on motor coordination was greatly attenuated in DMS-M ${ }_{4}-\mathrm{KD}$ mice (vs WT: Oxo-M treatment, $p<0.001)$. In the forced swim test, mice treated with Oxo-M exhibited a floating posture and the immobility time was significantly increased compared with that of vehicle-treated mice [vehicle: 0.89 $\pm 0.35 \mathrm{~min}$, Oxo-M: $2.34 \pm 0.39 \mathrm{~min}$; two-way ANOVA, interaction: $\mathrm{F}(1,28)=23.04, p<0.001]$. However, in ${ }_{D M S}-M_{4}-K D$ mice, the Oxo-M-induced increase in immobility time was diminished compared with Oxo-Mtreated WT mice (immobility time: $1.17 \pm 0.55 \mathrm{~min}, p<0.001$ ). Taken together, these results indicate that $\mathrm{M}_{4}$ receptors are necessary for striatal cholinergic modulation of DMS-related movement and behavioral performance.

\section{Altered Oxo-M-induced Cdk5 responses and glutamatergic synaptic transmission of MSNs in DMS-M ${ }_{4}-\mathrm{KD}$ mice}

In parallel with the behavioral testing, another set of mice received Oxo-M $(0.1 \mu \mathrm{M}, 2 \mu \mathrm{L}$, i.c.v $)$ for 3 consecutive days. Changes to Cdk5 in the DMS were then analyzed to determine if Cdk5 signaling was associated with $0 \times 0-M-$-related behavioral changes. Immunostaining revealed up-regulation of $\mathrm{Cdk} 5$ and p35/25 in a majority of $\mathrm{M}_{4}$-positive cells in the Oxo-M-treated DMS (Fig. 5a). Moreover, western blotting analysis of extracted protein from the eGFP-positive areas in the Oxo-M-treated DMS-M $\mathrm{M}_{4}-\mathrm{KD}$ mice revealed significant reductions in the levels of Cdk5 and $p 35 / 25$ by $58.91 \pm 9.12 \%$ and $45.44 \pm 7.21 \%$, respectively, compared with the levels in Oxo-M-treated WT mice ( $p<0.01$ and $p<0.05$, Fig. 5b). Similar results were found by confocal assays; Oxo-M increased Cdk5 and p35/25 expression in WT mice [vs WT: vehicle treatment, $F(3,36)=45.96, p<0.01$, Fig. $5 c$, d], whereas expression of Cdk5 and p35/25 was reduced specifically in $\mathrm{M}_{4}$-deleted neurons from the eGFP-positive areas of Oxo-M-treated DMS-KD-M4 mice (vs WT: Oxo-M treatment, $p<0.001$, Fig. $5 c, d$ ). These results confirmed that Cdk5 is an endogenous cholinergic M4 regulator in the DMS that impacts motor behavior. 
We then performed whole-cell recordings in brain slices prepared from the DMS of mice. mEPSCs were isolated as described above for isolated MSNs, and we recorded cells from the eGFP-positive areas in WT and DMS-M $\mathrm{M}_{4}-\mathrm{KD}$ mice. Characteristics exhibited by MSNs are shown in Fig. 5e. Bath application of Oxo-M $(10 \mu \mathrm{M})$ evoked similar inhibition of mEPSCs compared with that in isolated MSNs. There was an approximately $89.07 \pm 0.62 \%$ reduction in cumulative release probability in mEPSC frequency with $10 \mu \mathrm{M}$ Oxo-M ( $p<0.001$, Fig. $5 f)$. The Oxo-M-induced suppression of mEPSC frequency was impaired in slices from DMS-M $\mathrm{M}_{4}-\mathrm{KD}$ mice compared with that in WT mice. We also tested Cdk5 function on cholinergic inhibition in WT mice (Fig. 5g). ROSC alone did not alter mEPSCs. When we combined ROSC $(100,300$, $500 \mu \mathrm{M})$ with Oxo-M $(10 \mu \mathrm{M})$, ROSC $(500 \mu \mathrm{M})$ largely prevented the Oxo-M-induced suppression of mEPSC frequency; the inhibition of Oxo-M decreased by $55.45 \pm 0.13 \%$ in DMS-M $\mathrm{M}_{4}-\mathrm{KD}$ mice [vs WT: Oxo$M$ treatment, $F(3,36)=23.59, p<0.001$, Fig. 5h]. Electrophysiology findings indicated that the Cdk5 inhibitor and M4 deletion have the same tendency to inhibit cholinergic modulation of DMS synaptic transmission, suggesting $\mathrm{Cdk} 5$ involvement in $\mathrm{M}_{4}$-mediated cholinergic inhibition at glutamate terminals on striatal MSNs.

\section{Discussion}

The present results provide several lines of evidence for $\mathrm{M}_{4}$ being a major mAChR subtype mediating endogenous cholinergic inhibition of glutamatergic transmission of MSNs in the mouse DMS, and that Cdk5 is necessary for this modulation at the molecular and behavioral levels. Our findings provide new insight into the mechanism by which $\mathrm{Cdk} 5$ modulates $\mathrm{M}_{4}$-mediated cholinergic regulation of the striatal direct pathway.

In the present study, by using electrophysiological and pharmacological approaches in conjunction with genetic deletion of $M_{4}$ from cultured MSNs and intact brain preparations, we showed that $M_{4}$ mainly mediates the cholinergic inhibition of local striatal glutamatergic input. In isolated MSNs in which the $M_{4}$ gene was deleted, the inhibitory effect of Oxo-M on mEPSCs was completely absent. It is also worth noting that $\mathrm{M}_{4}$ deletion completed prevented the Oxo-M-mediated effect on mEPSCs in DMS brain tissue, indicating that $\mathrm{M}_{4}$ is a key mAChR subtype involved in cholinergic inhibition of glutamate release at the synapse throughout the DMS [28]. This is in line with previous reports and our findings support $\mathrm{M}_{4}$ being a major mAChR subtype mediating the cholinergic inhibition of corticostriatal glutamatergic input at corticostriatal synapses $[29,30]$.

We also showed that Oxo-M stimulated Cdk5, p25/p35 immunoreactivity and DARPP-32 Thr75 phosphorylation. The Cdk5 inhibitor, ROSC, suppressed both the Oxo-M-induced increase in Cdk5 and the Oxo-M-induced DARPP-32 Thr75 phosphorylation. Cdk5 is usually associated with its regulatory partners, p35 and p25. p25, a cleavage product of p35, results in hyperactivity of Cdk5 [31, 32]. We found that acute Oxo-M treatment concomitantly and significantly enhanced p35 and p25 expression in a dosedependent manner in MSNs. More importantly, PCC and MCC quantification confirmed a high degree of correlation between $\mathrm{M}_{4}$ and Cdk5 fluorophores in isolated MSNs. Furthermore, pharmacological block of 
$M_{4}$ receptors with MT3, or genetic deletion of M4 in MSNs, abolished Oxo-M-enhancement of Cdk5 and DARPP-32 Thr75 expression. These findings are consistent with our recent report showing that $M_{4}$ modulates DARPP-32 phosphorylation at Thr75 [17]. Interestingly, $\mathrm{M}_{4}$ receptors are expressed postsynaptically on striatonigral projection neurons (i.e., $\mathrm{D}_{1}-\mathrm{MSNs}$ ) and interneurons $[33,34]$. Thus, our findings indicate that Cdk5/P35 and DARPP-32 signaling mediate endogenous cholinergic modulation through $\mathrm{M}_{4}$ in striatonigral neurons. We therefore speculated that Cdk5/p35 activity is required for $\mathrm{M}_{4^{-}}$ related physiological processes, directly or indirectly. As predicted, a Cdk5 inhibitor partly abolished the inhibitory effect of Oxo-M on mEPSCs recorded from isolated MSNs, indicating that Cdk5 also contributes to $\mathrm{OxO}-\mathrm{M}$-induced glutamatergic transmission of striatal neurons. These data provide strong evidence that Cdk5 is necessary in cholinergic circuit-level mechanisms of the striatum.

In the present study, we also generated mutant mice lacking M4 in the DMS (DMS-M $\left.{ }_{4}-K D\right)$. The DMS was chosen because of its important role in processing and integration of motor behavior. Two weeks after LV/Cas9 $\mathrm{M}_{4}$-sgRNA injection, we evaluated the motor activity of WT, NC and DMS-M ${ }_{4}-K D$ mice by testing locomotor activity, motor coordination, and swimming performance. Interestingly, normal baseline behavioral activity was observed in all DMS-M $\mathrm{M}_{4}-\mathrm{KD}$ mice. However, $\mathrm{M}_{4}$ deletion in the DMS significantly impaired behavioral responses evoked by Oxo-M. In parallel with behavioral changes, Oxo-M, a muscarinic acetylcholine receptor agonist, promoted Cdk5 signaling and DARPP-32 activity in DSM MSNs in vitro, but failed in DMS-M $-\mathrm{KD}$ mice. It is noteworthy that the M4-mediated inhibition of glutamatergic transmission involved biochemical changes of Cdk5 in striatonigral neurons in WT mice, while the inhibitory effect of Oxo-M on glutamatergic transmission was completely absent in DMS-M $\mathrm{M}_{4}-\mathrm{KD}$ mice. This led us to conclude that Cdk5 is the key intracellular signaling mechanism underlying $\mathrm{M}_{4}$ mAChR modulation in the striatum and various behavioral responses. In addition to this novel modulation of $\mathrm{M}_{4} \mathrm{mAChR}$ in normal physiological functions, pathological roles for Cdk5 have been claimed in the aging and degenerating brain. Cdk5 activity is dysregulated in various brain disorders resulting in profound remodeling of the neuronal cytoskeleton, loss of synapses, and ultimately neurodegeneration [31,32]. Thus, further research is needed to elucidate the complexity of striatal network regulation by $\mathrm{M}_{4}$ and the Cdk5/P25 signaling pathway, and to dissect its effects on neuronal cytoskeleton remodeling, which might be involved in Parkinson's disease pathogenesis.

\section{Conclusion}

Our findings reveal a novel regulatory mechanism that is critical for Cdk5/P35 and DARPP-32 signaling to mediate endogenous cholinergic $\mathrm{M}_{4}$ modulation on striatonigral neurons and to affect motor behavior. Furthermore, we suggest that striatal circuits may, in part, be controlled by $\mathrm{M}_{4}$ through its modulation of Cdk5-DARPP-32 activity, which is disrupted in the pathological conditions of PD.

\section{Abbreviations}


ACh, acetylcholine; Oxo-M, oxotremorine $M$; $m A C h R s$, muscarinic acetylcholine receptors; $D_{1}$, dopamine $D_{1}$ receptor; $M_{4}$, muscarinic acetylcholine 4 receptor; DARPP-32, dopamine- and cAMP-regulated phosphoprotein, Mr 32 kDa; KD, knockdown; MSNs, medium spiny neurons; PKA, protein kinase A; PBS, phosphate buffered saline; DMS, dorsomedial striatum; CRISPR-Cas9, clustered regularly interspaced short palindromic repeats-associated protein 9; sgRNA, single-guide RNA; eGFP, enhanced green fluorescent protein; i.p., intraperitoneally; i.c.v., intracerebroventricular; WT, wild type; NC, negative control; FST, forced swimming test; mEPSC, miniature excitatory postsynaptic current; ACSF, artificial cerebrospinal fluid; TTX, tetrodotoxin; PAM, positive allosteric modulator; Cdk5, cyclin-dependent kinase 5; AP, anteroposterior; ML, mediolateral; DV, dorsoventral; SDS, sodium dodecyl sulfate; ANOVA, analysis of variance; LV, lentiviral; PD, Parkinson's disease

\section{Declarations}

\section{Authors' contributions}

Liyun Wang, Yongan Wang and Jin Li conducted the study and wrote the manuscript; Hu Zhou collected data, performed statistical analysis, and prepared figures; Huaxiang Shi, Xing Li, Xin Sui, Zhe Zhao, and Jingxin Zhang designed and performed experiments.

All authors read and approved the final manuscript.

\section{Acknowledgements}

We thank Shuzhuo Zhang for helping with electrophysiology. We thank Liwen Bianji, Edanz Editing China (www.liwenbianji.cn/ac) for editing the English text of a draft of this manuscript.

\section{Ethics approval and consent to participate}

Not applicable

\section{Consent for publication}

Not applicable

\section{Availability of data and materials}

The datasets used and/or analyzed during the current study are available from the corresponding author on reasonable request. 


\section{Funding}

This work was supported by the National Megaproject of Science Research of China (2018ZX09301-006) and the National Integrated Drug Discovery Technology Platform Foundation of China (2012ZX09301003).

\section{Competing interests}

The authors declare no competing financial interests.

\section{References}

1. Obeso JA, Rodriguez-Oroz MC, Rodriguez M, Lanciego JL, Artieda J, Gonzalo N, Olanow CW: Pathophysiology of the basal ganglia in Parkinson's disease. Trends Neurosci 2000, 23:S8-19.

2. Di Chiara G, Morelli M, Consolo S: Modulatory functions of neurotransmitters in the striatum: ACh/dopamine/NMDA interactions. Trends Neurosci 1994, 17:228-233.

3. Aosaki T, Miura M, Suzuki T, Nishimura K, Masuda M: Acetylcholine-dopamine balance hypothesis in the striatum: an update. Geriatr Gerontol Int 2010, 10 Suppl 1:S148-157.

4. Graybiel AM: The basal ganglia. Curr Biol 2000, 10:R509-511.

5. Yin $\mathrm{HH}$, Knowlton BJ, Balleine BW: Inactivation of dorsolateral striatum enhances sensitivity to changes in the action-outcome contingency in instrumental conditioning. Behav Brain Res 2006, 166:189-196.

6. Jin X, Costa RM: Shaping action sequences in basal ganglia circuits. Curr Opin Neurobiol 2015, 33:188-196.

7. Wall NR, De La Parra M, Callaway EM, Kreitzer AC: Differential innervation of direct- and indirectpathway striatal projection neurons. Neuron 2013, 79:347-360.

8. Cui G, Jun SB, Jin X, Pham MD, Vogel SS, Lovinger DM, Costa RM: Concurrent activation of striatal direct and indirect pathways during action initiation. Nature 2013, 494:238-242.

9. Tecuapetla F, Jin X, Lima SQ, Costa RM: Complementary Contributions of Striatal Projection Pathways to Action Initiation and Execution. Cel/ 2016, 166:703-715.

10. Hersch SM, Gutekunst CA, Rees HD, Heilman CJ, Levey Al: Distribution of m1-m4 muscarinic receptor proteins in the rat striatum: light and electron microscopic immunocytochemistry using subtypespecific antibodies. J Neurosci 1994, 14:3351-3363.

11. Kreitzer AC: Physiology and pharmacology of striatal neurons. Annu Rev Neurosci 2009, 32:127-147.

12. Hernandez-Flores T, Hernandez-Gonzalez O, Perez-Ramirez MB, Lara-Gonzalez E, Arias-Garcia MA, Duhne M, Perez-Burgos A, Prieto GA, Figueroa A, Galarraga E, Bargas J: Modulation of direct pathway striatal projection neurons by muscarinic M(4)-type receptors. Neuropharmacology 2015, 89:232244. 
13. Fernandez E, Schiappa R, Girault JA, Le Novere N: DARPP-32 is a robust integrator of dopamine and glutamate signals. PLoS Comput Biol 2006, 2:e176.

14. Kuroiwa M, Hamada M, Hieda E, Shuto T, Sotogaku N, Flajolet M, Snyder GL, Hendrick JP, Fienberg A, Nishi A: Muscarinic receptors acting at pre- and post-synaptic sites differentially regulate dopamine/DARPP-32 signaling in striatonigral and striatopallidal neurons. Neuropharmacology 2012, 63:1248-1257.

15. Fienberg AA, Hiroi N, Mermelstein PG, Song W, Snyder GL, Nishi A, Cheramy A, O'Callaghan JP, Miller DB, Cole DG, et al: DARPP-32: regulator of the efficacy of dopaminergic neurotransmission. Science 1998, 281:838-842.

16. Bibb JA, Snyder GL, Nishi A, Yan Z, Meijer L, Fienberg AA, Tsai LH, Kwon YT, Girault JA, Czernik AJ, et al: Phosphorylation of DARPP-32 by Cdk5 modulates dopamine signalling in neurons. Nature 1999, 402:669-671.

17. Liu L, Huang Y, Huang Q, Zhao Z, Yu J, Wang L: Muscarinic acetylcholine M4 receptors play a critical role in oxotremorine-induced DARPP-32 phosphorylation at threonine 75 in isolated medium spiny neurons. Neuropharmacology 2017, 117:376-386.

18. Hart G, Leung BK, Balleine BW: Dorsal and ventral streams: the distinct role of striatal subregions in the acquisition and performance of goal-directed actions. Neurobiol Learn Mem 2014, 108:104-118.

19. Howe MW, Dombeck DA: Rapid signalling in distinct dopaminergic axons during locomotion and reward. Nature 2016, 535:505-510.

20. Do J, Kim Jl, Bakes J, Lee K, Kaang BK: Functional roles of neurotransmitters and neuromodulators in the dorsal striatum. Learn Mem 2012, 20:21-28.

21. Calabresi P, Gubellini P, Centonze D, Picconi B, Bernardi G, Chergui K, Svenningsson P, Fienberg AA, Greengard P: Dopamine and cAMP-regulated phosphoprotein $32 \mathrm{kDa}$ controls both striatal long-term depression and long-term potentiation, opposing forms of synaptic plasticity. J Neurosci 2000 , 20:8443-8451.

22. Bogdanova OV, Kanekar S, D'Anci KE, Renshaw PF: Factors influencing behavior in the forced swim test. Physiol Behav 2013, 118:227-239.

23. Li X, Zhou H, Yang P, Shi HX, Xiong Y, Nie ZY, Yu JQ, Wang YA, Zhou R, Wang LY: Cyclin-dependent Kinase 5 Regulates Cortical Neurotransmission and Neural Circuits Associated with Motor Control in the Secondary Motor Cortex in the Mouse. Neuroscience 2020, 438:9-24.

24. Mao M, Nair A, Augustine GJ: A Novel Type of Neuron Within the Dorsal Striatum. Front Neural Circuits 2019, 13:32.

25. Azzi L, Meijer L, Ostvold AC, Lew J, Wang JH: Purification of a 15-kDa cdk4- and cdk5-binding protein. J Biol Chem 1994, 269:13279-13288.

26. Tsai LH, Delalle I, Caviness VS, Jr., Chae T, Harlow E: p35 is a neural-specific regulatory subunit of cyclin-dependent kinase 5. Nature 1994, 371:419-423.

27. Tang D, Yeung J, Lee KY, Matsushita M, Matsui H, Tomizawa K, Hatase O, Wang JH: An isoform of the neuronal cyclin-dependent kinase 5 (Cdk5) activator. J Biol Chem 1995, 270:26897-26903. 
28. Pancani T, Bolarinwa C, Smith Y, Lindsley CW, Conn PJ, Xiang Z: M4 mAChR-mediated modulation of glutamatergic transmission at corticostriatal synapses. ACS Chem Neurosci 2014, 5:318-324.

29. Alger BE, Nagode DA, Tang AH: Muscarinic cholinergic receptors modulate inhibitory synaptic rhythms in hippocampus and neocortex. Front Synaptic Neurosci 2014, 6:18.

30. Gonzalez JC, Albinana E, Baldelli P, Garcia AG, Hernandez-Guijo JM: Presynaptic muscarinic receptor subtypes involved in the enhancement of spontaneous GABAergic postsynaptic currents in hippocampal neurons. Eur J Neurosci 2011, 33:69-81.

31. Tarricone C, Dhavan R, Peng J, Areces LB, Tsai LH, Musacchio A: Structure and regulation of the CDK5-p25(nck5a) complex. Mol Cell 2001, 8:657-669.

32. Zhuang L, Yu BW: [The role of Cdk5 in learning and memory]. Sheng Li Ke Xue Jin Zhan 2010, 41:141-143.

33. Ince E, Ciliax BJ, Levey Al: Differential expression of D1 and D2 dopamine and m4 muscarinic acetylcholine receptor proteins in identified striatonigral neurons. Synapse 1997, 27:357-366.

34. Santiago MP, Potter LT: Biotinylated m4-toxin demonstrates more M4 muscarinic receptor protein on direct than indirect striatal projection neurons. Brain Res 2001, 894:12-20.

\section{Figures}

a

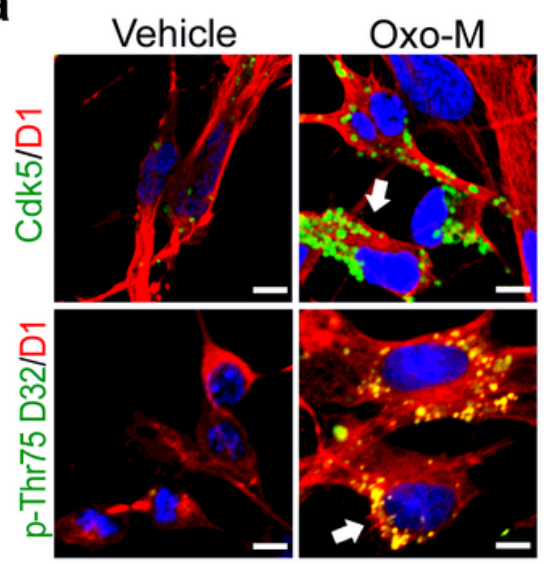

C

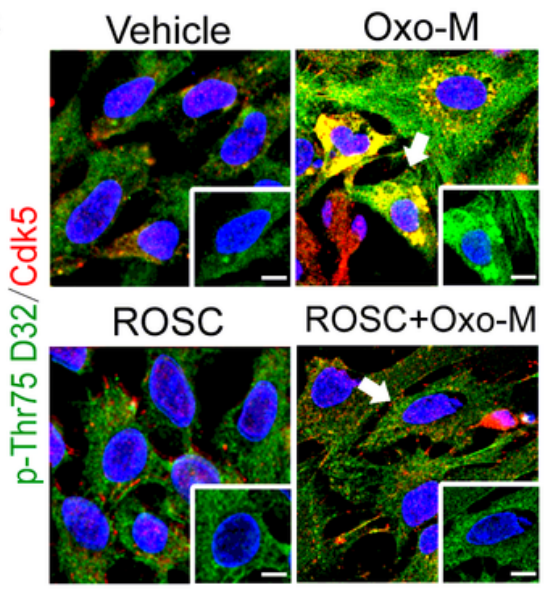

b
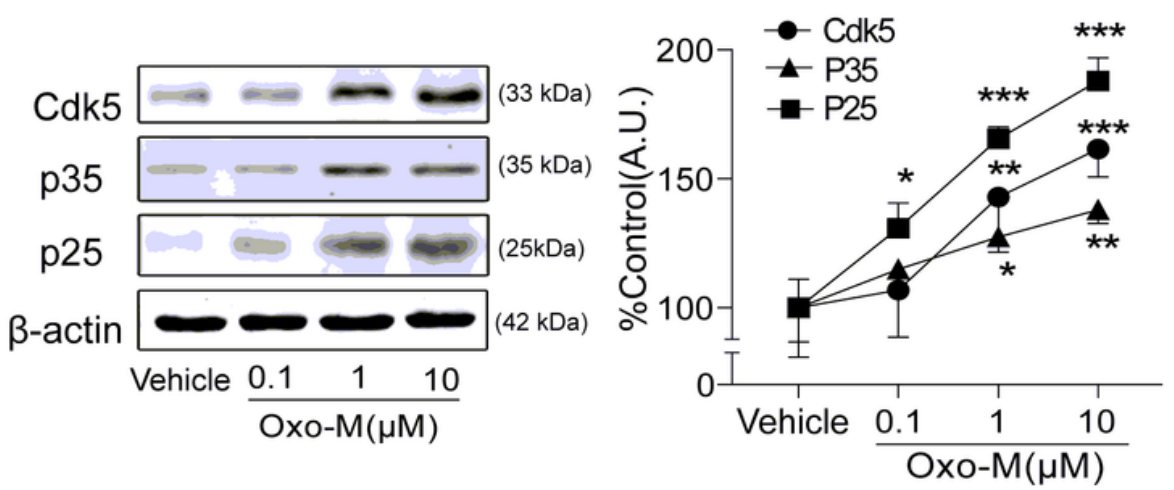

d

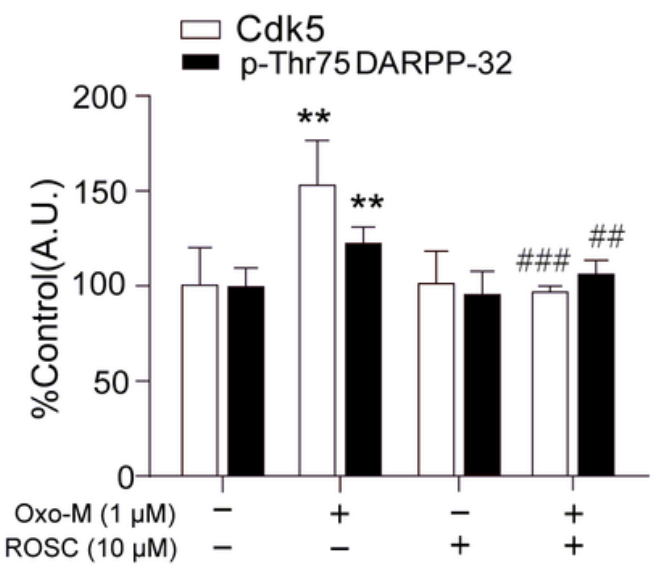




\section{Figure 1}

Oxo-M increases Cdk5 and p-Thr75 D32 expression in D1-MSNs studied in vitro. (a) MSNs were incubated with $1 \mu \mathrm{M}$ Oxo-M for $15 \mathrm{~min}$, and immunolabeled with antibodies against DARPP-32 p-Thr75 or Cdk5. The immunoreactive labeling of DARPP-32 p-Thr75 and Cdk5 was determined by confocal microscopy. The arrows indicate increased Cdk5 and DARPP-32 p-Thr75 expression in 0xo-M-treated D1-MSNs (red). Scale bars represent $10 \mu \mathrm{m}$. (b) Qualitative and quantitative changes in profiles of Cdk5 and its activator p35/25 detected by western blot analysis. MSNs were incubated with Oxo-M at 0.1, 1, $10 \mu \mathrm{M}$ for $15 \mathrm{~min}$. Cells were lysed and western blotting revealed Oxo-M increased the levels of Cdk5 and p35/25 in a dosedependent manner. (c) MSNs were treated with Cdk5 inhibitor, ROSC (10 $\mu \mathrm{M})$, for 10 min, followed by the addition of $1 \mu \mathrm{M}$ Oxo-M for $15 \mathrm{~min}$. Qualitative changes in Cdk5 and DARPP-32 p-Thr75 were determined by confocal microscopy. Scale bars represent $10 \mu \mathrm{m}$. (d) Western blot analysis of changes following OxoM-induced Cdk5/DARPP-32 p-Thr75 in the presence of ROSC. Data are presented as the mean \pm S.E.M. *P

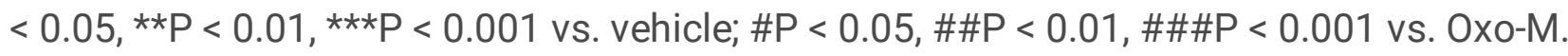


a
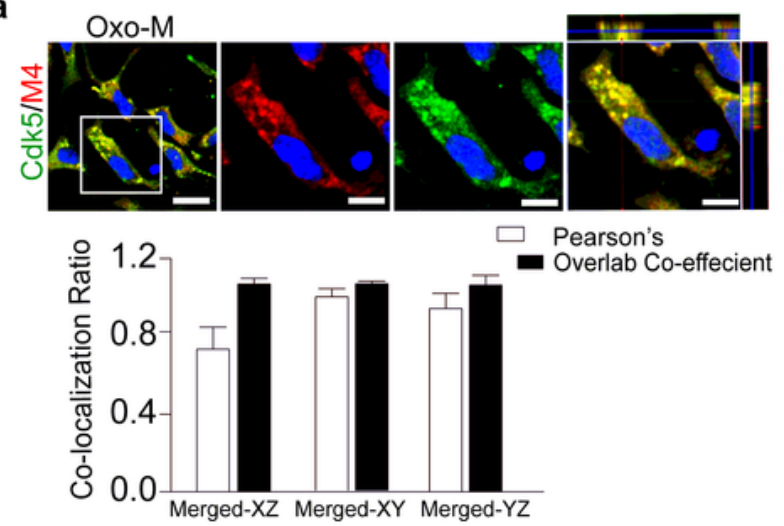

C
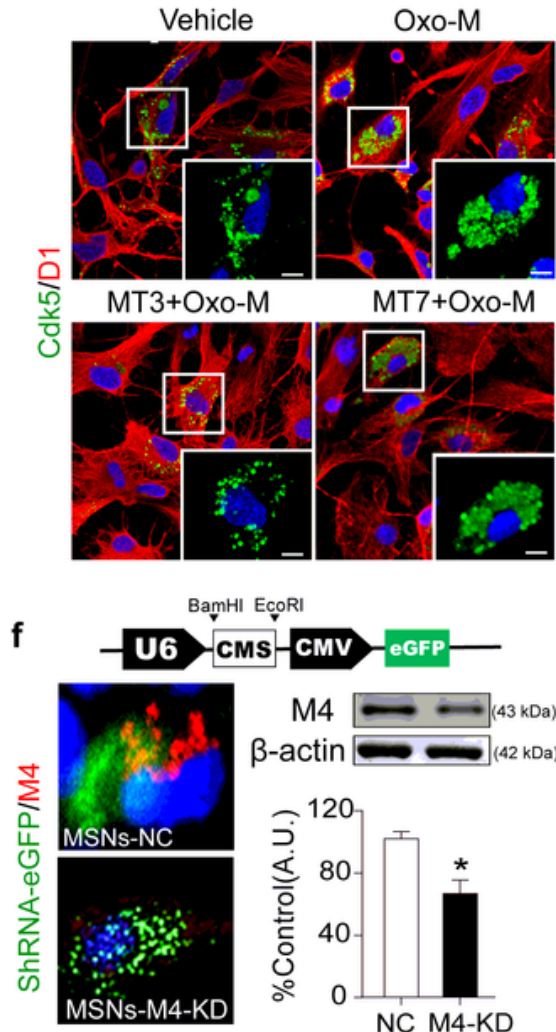

ạ̧HI Eçorl

e h

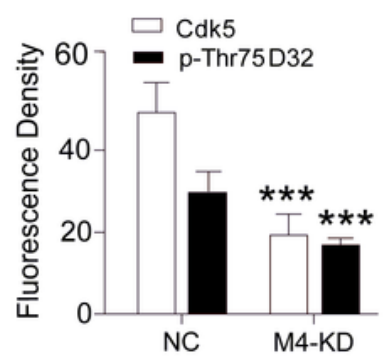

b

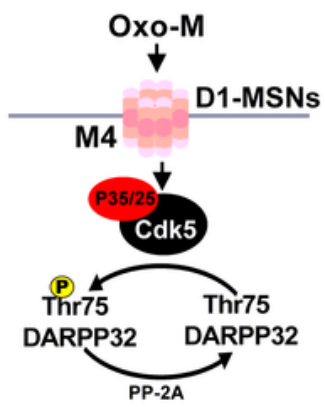

d Cdk5 $-\ldots-(33 \mathrm{kDa})$ Cdk5 $-\cdots-{ }^{(33 \mathrm{kDa})}$

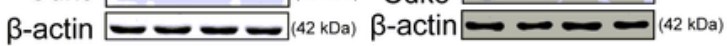
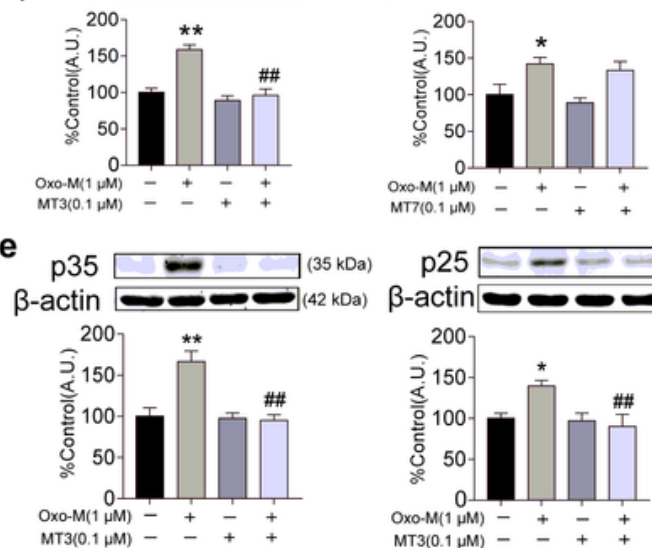

p25
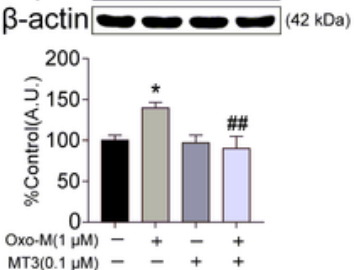

g Oxo-M Merged ShRNA-eGFP Cdk5

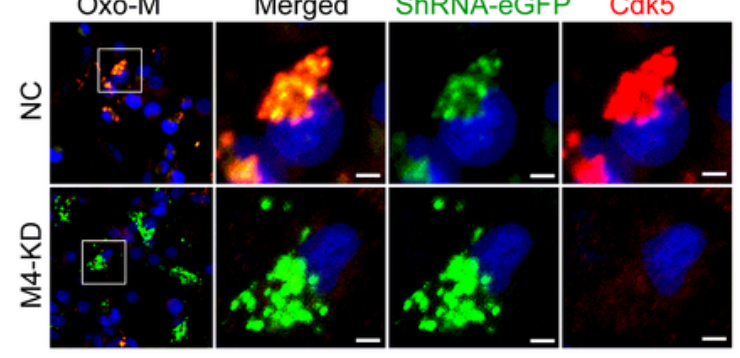

Oxo-M

Merged ShRNA-eGFP p-Thr75 D32

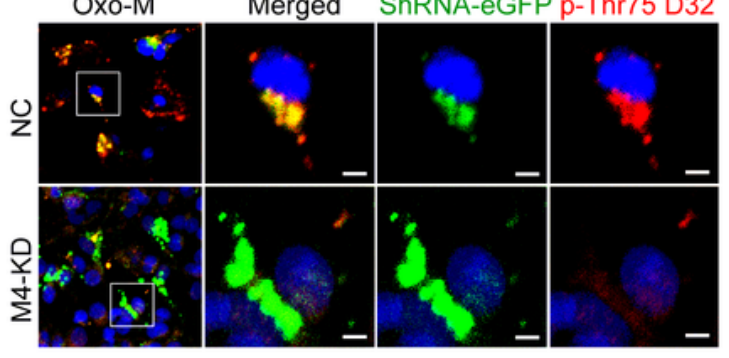

\section{Figure 2}

Pharmacological block and knockdown of M4 receptors suppress 0xo-M-induced Cdk5/DARPP-32 pThr75 expression in isolated MSN. (a) MSNs were immunolabeled with monoclonal antibodies against Cdk5 and M4. Whole cell scanning to determine PCC and MCC values revealed Cdk5 colocalization with M4 in the presence of Oxo-M in MSNs. Scale bars represent $10 \mu \mathrm{m}$. (b) Schematic of the experimental hypothesis: Oxo-M-induced Cdk5/DARPP-32 p-Thr75 expression mediates M4 cholinergic transmission at 
the cellular level. (c) MSNs were pretreated with antagonists for M4 (MT3, $0.1 \mu \mathrm{M})$ or M1 (MT7, $0.1 \mu \mathrm{M})$ for $10 \mathrm{~min}$ and then treated with Oxo-M $(1 \mu \mathrm{M})$ for $15 \mathrm{~min}$. Cdk5 levels were determined by confocal microscopy, and magnified views of Cdk5 immunoreactivity revealed that MT3 but not MT7 can abolish Oxo-M-induced Cdk5 expression instead. Scale bars are $20 \mu \mathrm{m}$. (d) Qualitative and quantitative changes in Cdk5 analyzed by western blotting. (e) Western blotting of Cdk5 activator, p35/25. MT3 abolished OxoM-induced P35/25 upregulation. (f) Structure of the lentiviral pGMLV-SC5 RNA vector containing shRNA targeting M4 receptors (upper). The levels of M4 were detected by confocal microscopy and western blotting after LV-Chrm4-shRNA transfection (lower). (g) Cdk5 and DARPP-32 p-Thr75 immunoreactivity in NC and KD-M4 MSNs after administration of Oxo-M (1 $\mu \mathrm{M})$ for 15 min observed by confocal microscopy. (h) Quantitative analysis of Cdk5 and DARPP-32 p-Thr75 immunoreactivity showing Oxo-M activated Cdk5/DARPP-32 p-Thr75 expression dependent on M4. Data are presented as the mean \pm S.E.M. ${ }^{*} \mathrm{P}<$ $0.05,{ }^{\star} * \mathrm{P}<0.01,{ }^{* \star *} \mathrm{P}<0.001$ vs. vehicle; $\# \mathrm{P}<0.05, \# \# \mathrm{P}<0.01, \# \# \# \mathrm{P}<0.001$ vs. Oxo-M. 
a

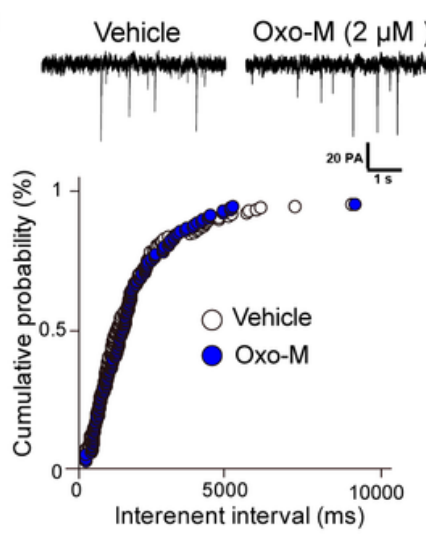

C
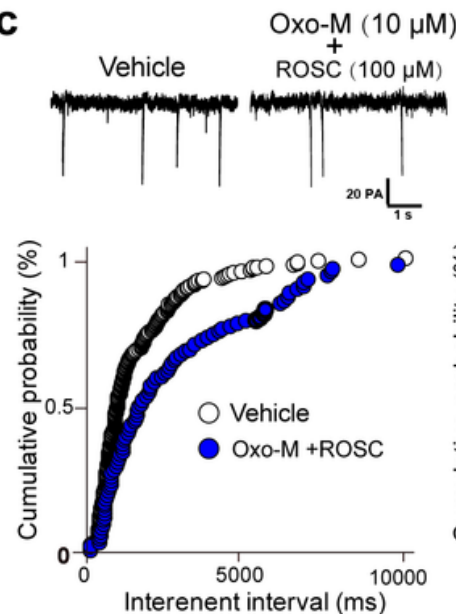

Interenent interval (ms)

e

M4-KD MSNs

Rec.

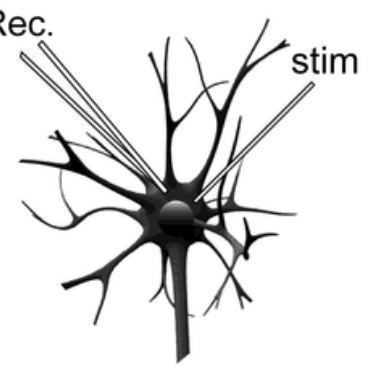

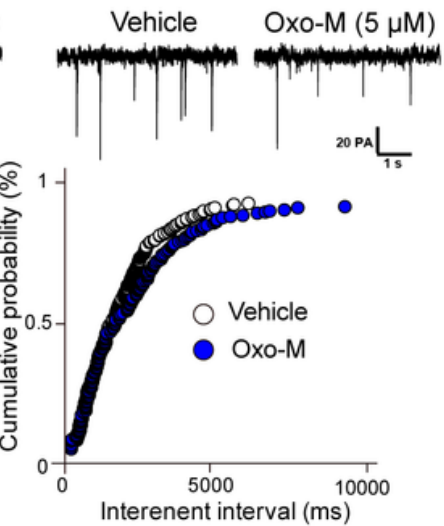
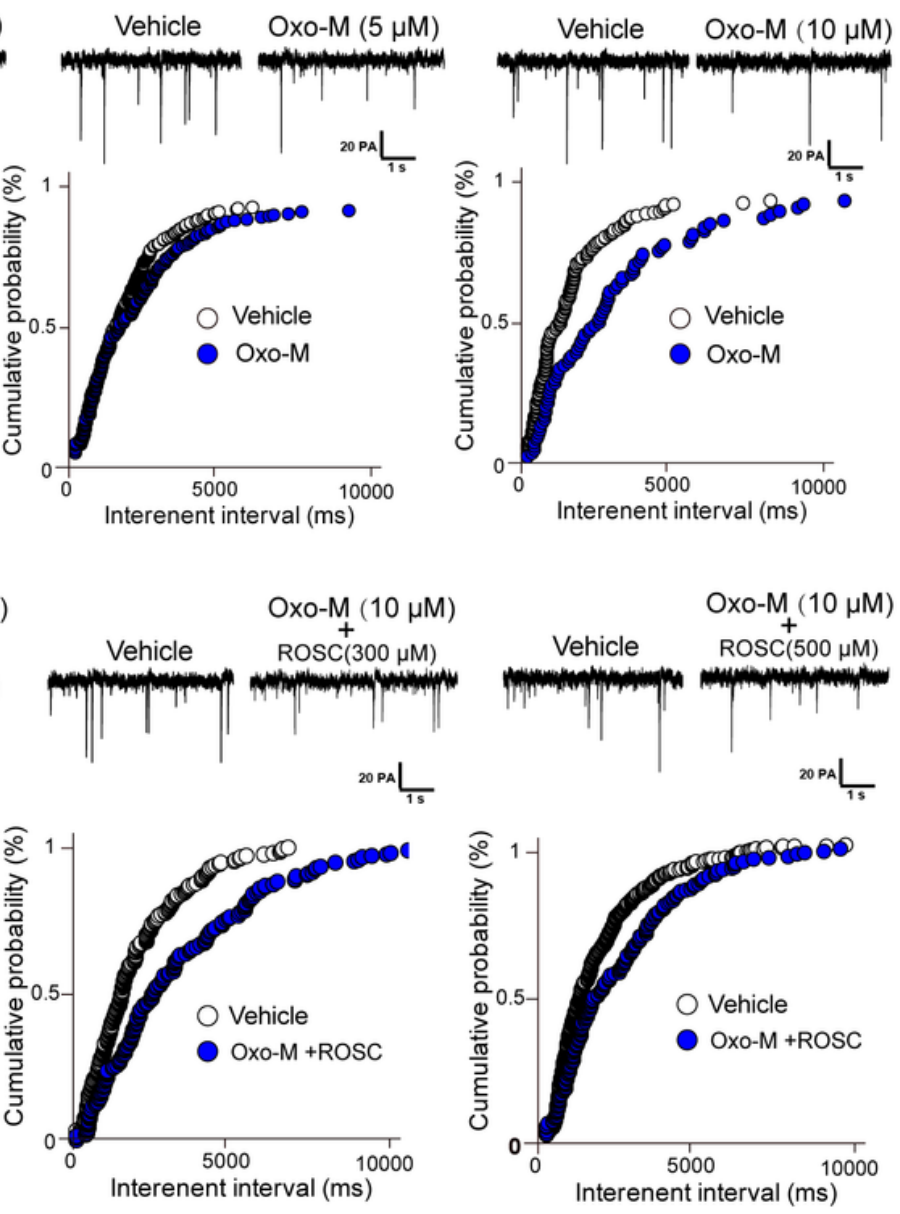

f

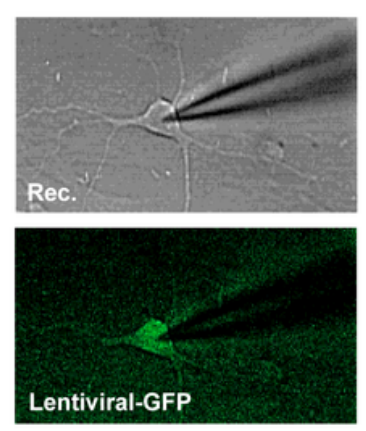

b

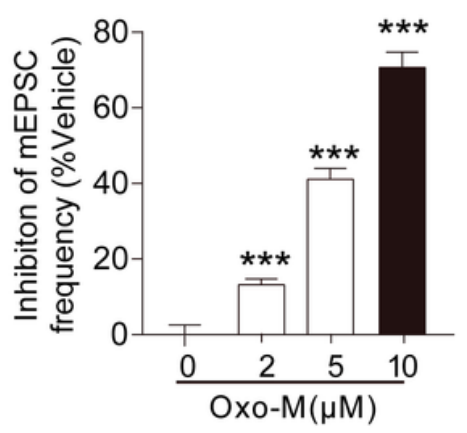

d

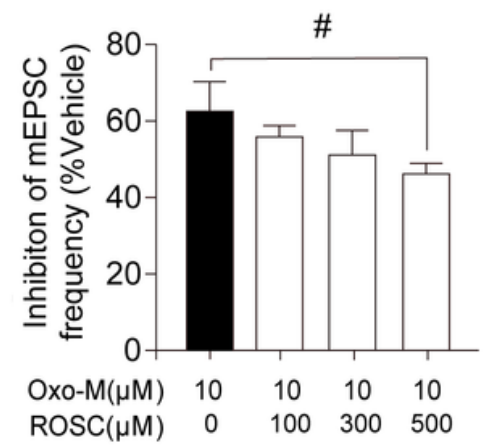

g
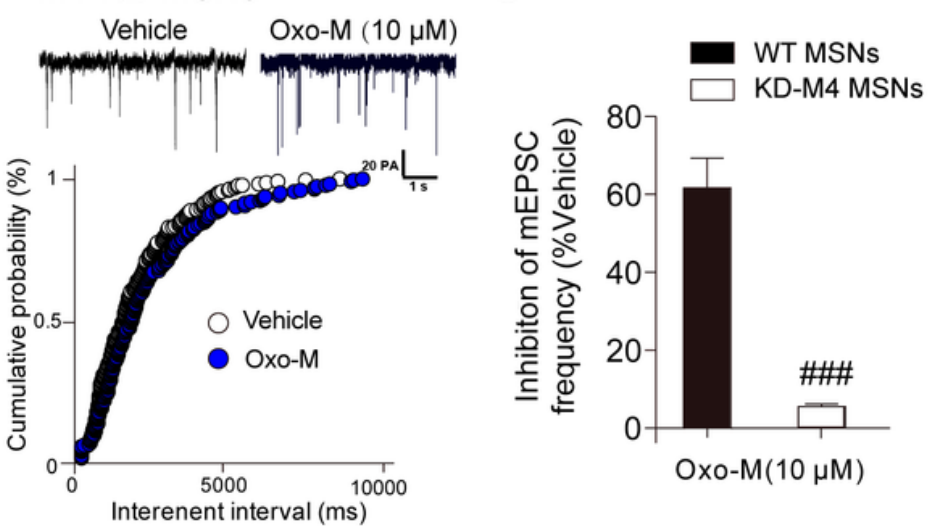

Figure 3

Effect of M4 and Cdk5 on Oxo-M-induced mEPSCs in MSNs studied in vitro. (a) Representative mEPSC traces and cumulative probability plots from cultured primary MSNs treated with vehicle (ACSF) or Oxo-M $(2 \mu \mathrm{M}, 5 \mu \mathrm{M}, 10 \mu \mathrm{M})$. Calibration: 20 pA, $1 \mathrm{~s}$. (b) Quantification of data represented in (a) revealed Oxo-M decreased mEPSC frequency compared with the response to vehicle. (c) Representative mEPSC traces and cumulative probability plots from MSNs treated with $10 \mu \mathrm{M}$ Oxo-M and 100, 300 or $500 \mu \mathrm{M}$ ROSC. Calibration: 20 pA, 1 s. (d) Quantification of data represented in (c) revealed that ROSC prevented $10 \mu \mathrm{M}$ Oxo-M-induced suppression of mEPSC frequency in a dose-dependent manner. (e) Representative bright 
field image (left) and fluorescence image (right) of an M4 knockdown MSN (M4-KD MSN) undergoing recording. Rec.: recording electrode, stim.: drug stimulation. (f) Representative mEPSC traces and cumulative probability plots from M4-KD MSNs treated with $10 \mu \mathrm{M}$ Oxo-M. Calibration: 20 pA, $1 \mathrm{~s}$. A summary of the data are presented. (g) Quantification of data represented in (f). Negative modulation corresponds to Oxo-M with decreased mEPSC frequency in WT MSNs that is abolished in M4-KD MSNs. Data are presented as the mean \pm S.E.M. ${ }^{*} P<0.05,{ }^{\star *} \mathrm{P}<0.01$, ${ }^{\star \star \star} \mathrm{P}<0.001$ vs. vehicle; $\# \mathrm{P}<0.05, \# \# \mathrm{P}<$ $0.01, \# \# \#$ P 0.001 vs. Oxo-M.

a

LV/Cas9-sgRNA microinjection in DMS

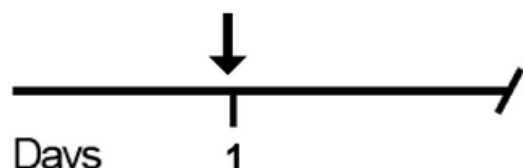

Days vehicle or Oxo-M(0.1 $\mu \mathrm{M})$

intra-cerebroventricular injection

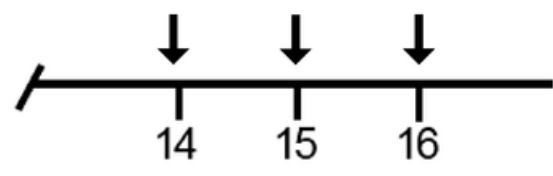

Locomotor activity

Rotarod testing

Forced swimming

b
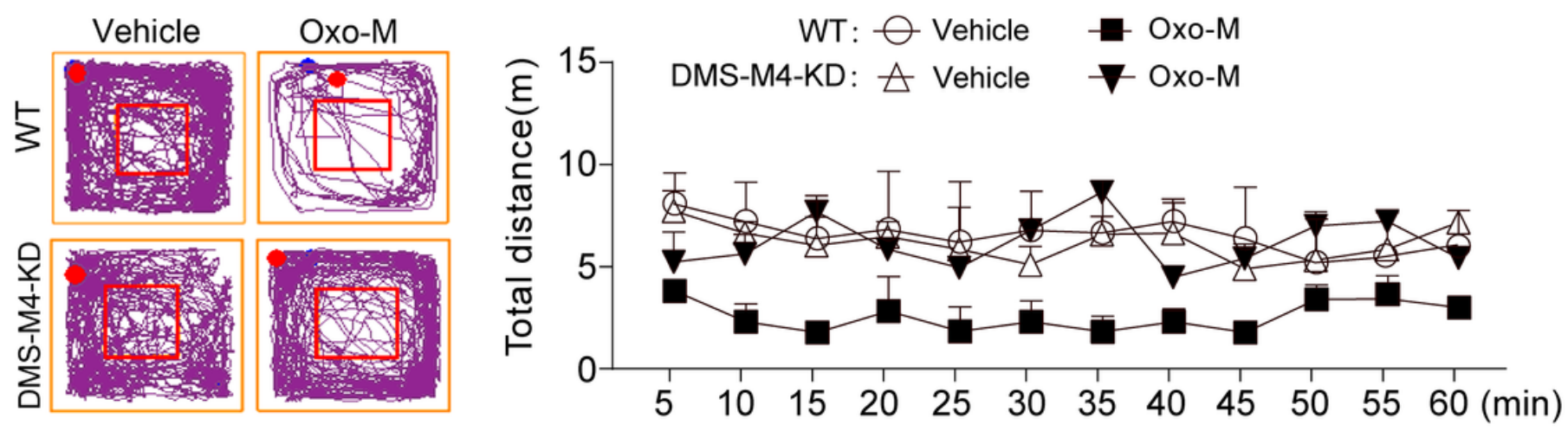

C

Locomotor activity test

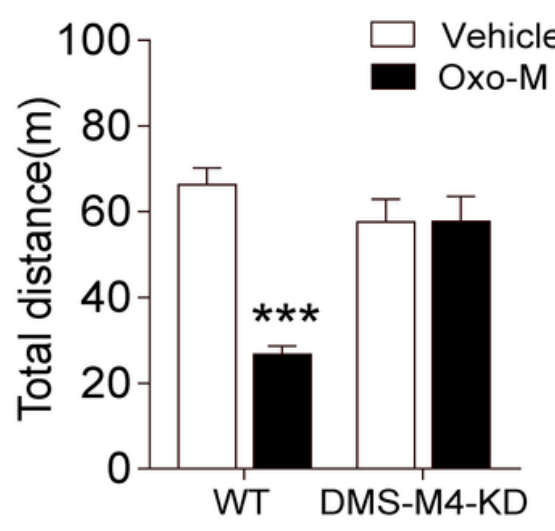

d

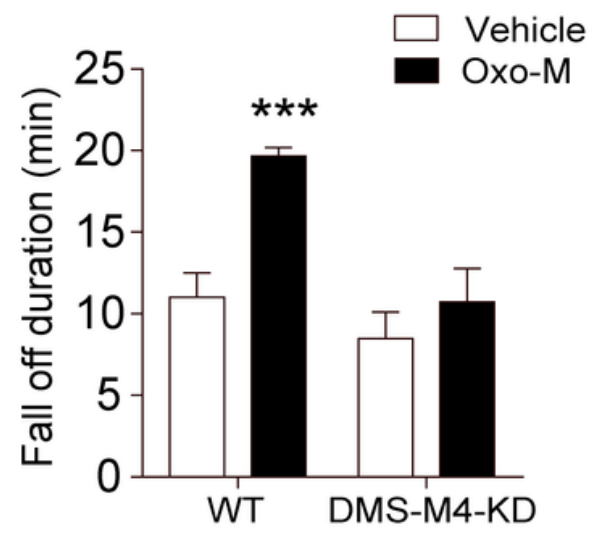

e

Foreced Swimming test

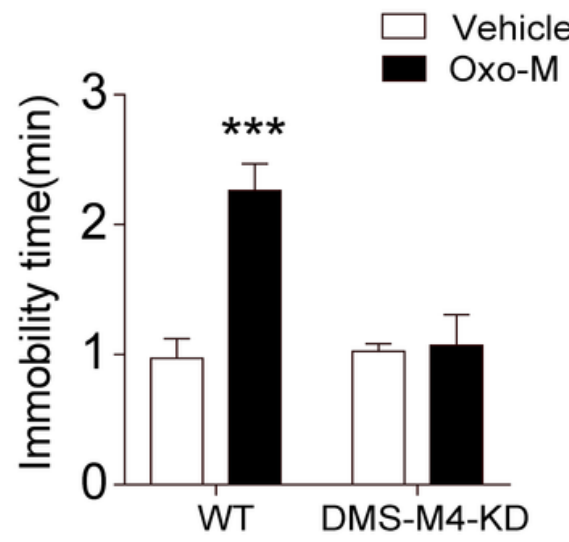

Figure 4

Behavioral responses to Oxo-M are altered in DMS-M4-KD mic. WT and DMS-M4-KD mice were directly injected with Oxo-M $(0.1 \mu \mathrm{M}, 2 \mu \mathrm{L}$, i.c.v) into the lateral ventricle on 3 consecutive days and the behavioral 
response investigated via locomotion activity, forced swim and rotarod tests. (a) Timeline of behavior testing. The behavior testing was performed 14 days after LV/Cas9-sgRNA transduction. (b) Left panel: activity tracking. Right panel: locomotion activity was recorded for $60 \mathrm{~min}$ and is reported as distance in meters $(\mathrm{m})$ per $5 \mathrm{~min}$. (c-e) Quantitative analysis of the total distance traveled in the locomotor activity test (c), fall off duration in the rotarod test (d), and immobility time in the forced swim test (e). Oxo-M significantly affected motor behavior performance in WT mice, which was attenuated in DMS-M4-KD

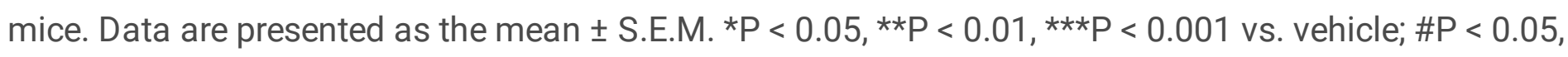
$\# \# \mathrm{P}<0.01, \# \# \# \mathrm{P}<0.001$ vs. Oxo-M. 


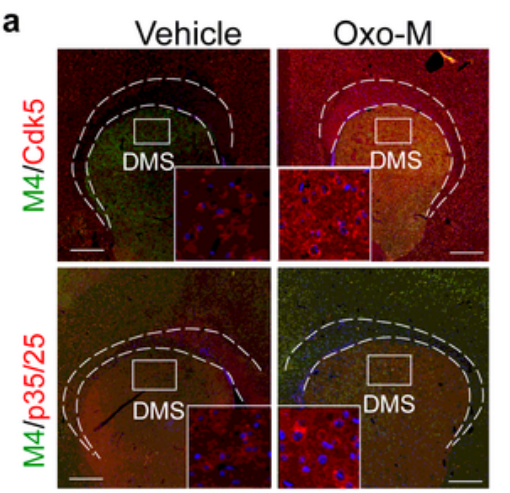

c

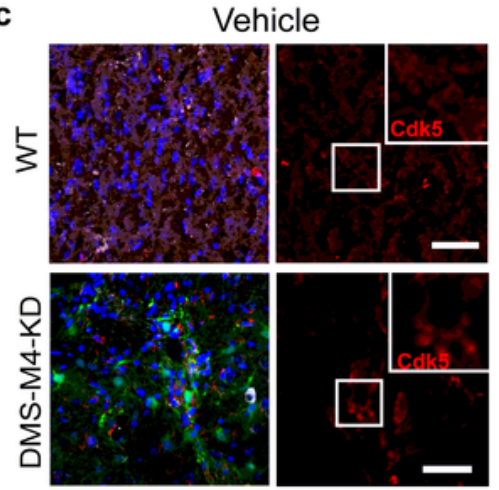

Lv/Cas9 shRNA-eGFP/M4/Cdk5
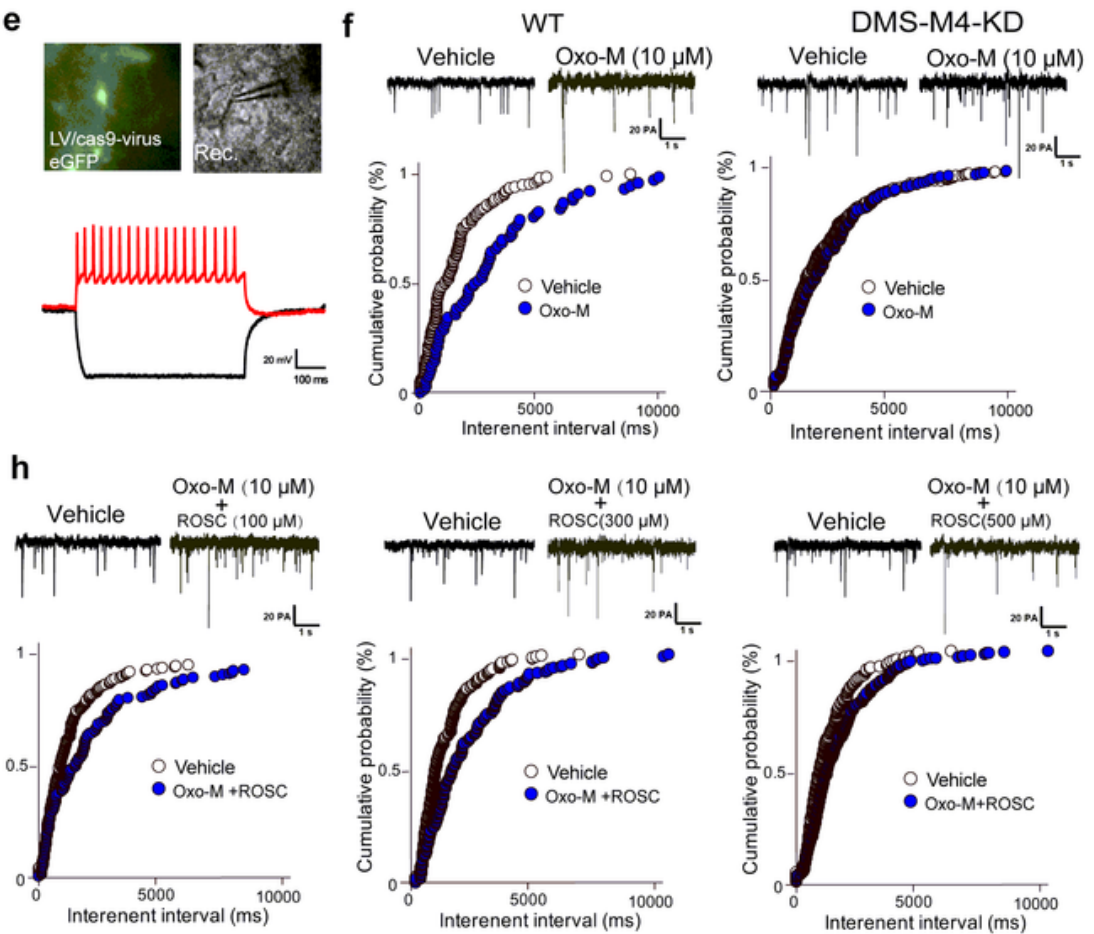

Oxo-M
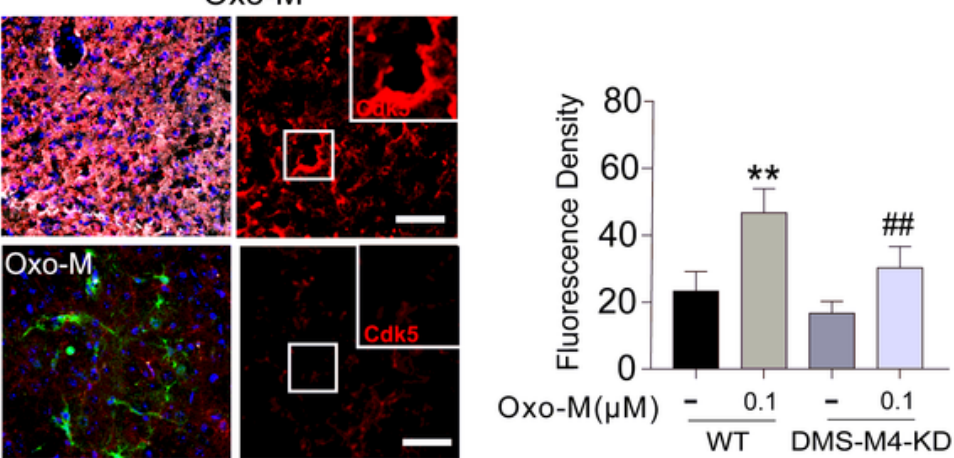

d
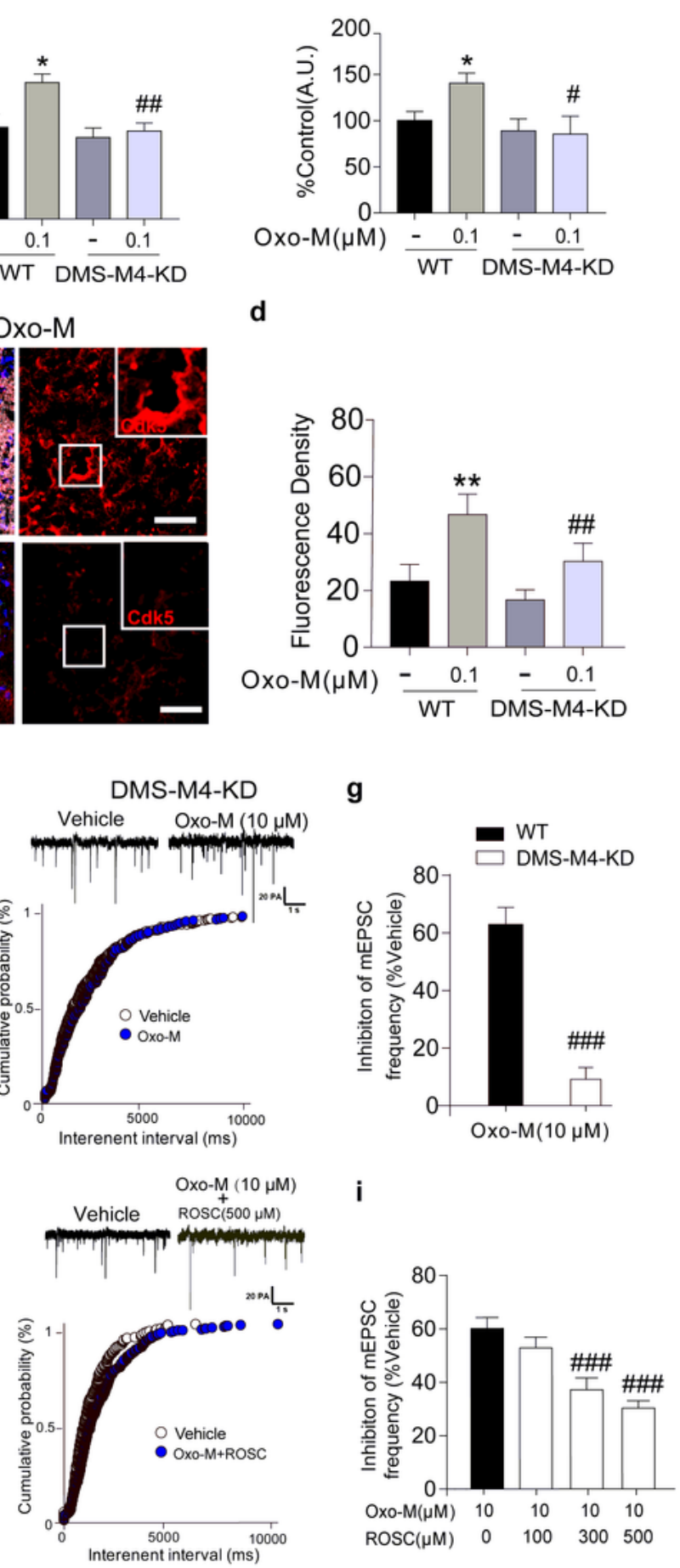

\section{Figure 5}

Oxo-M-induced Cdk5 signaling and glutamatergic synaptic transmission of MSNs are altered in DMS-KDM4 mice. After behavioral testing, the brains of WT and DMS-M4-KD mice were immediately taken for biochemical analysis. (a) Changes of Cdk5 and p25/35 levels were observed using confocal microscopy. The white boxes are magnified views of Cdk5/P35/25, which indicate that Oxo-M increased the levels of Cdk5 and P35/25 in the region of infection. Scale bars represent 500 and $50 \mu \mathrm{m}$. (b) Qualitative and 
quantitative changes of Cdk5 and DARPP-32 p-Thr75 analyzed by western blot analysis. (c) Expression of Cdk5 and M4 in LV/Cas9-sgRNA-infected DMS of DMS-M4-KD mice was observed using confocal microscopy. (d) Quantitative analysis of Cdk5 fluorescence shows that Oxo-M increased the level of Cdk5 in WT mice, but this was impaired in DMS-M4-KD mice. (e) Schematic diagram of the whole-cell recording position and representative LV/eGFP fluorescence image in WT and DMS-M4-KD brain slices (upper).

MSN-specific action potential traces from MSNs (lower). (f) Representative mEPSC traces and cumulative probability plots from neurons of the striatum slices treated with vehicle or $10 \mu \mathrm{M}$ Oxo-M in WT and DMSKD-M4 mice. Calibration: 20 pA, 1 s. (g) Quantification of data revealed M4 knockdown in DMS significantly prevented $10 \mu \mathrm{M}$ Oxo-M-induced suppression of mEPSC frequency. (h) mEPSC traces and cumulative probability plots from neurons of the striatum slices treated with $10 \mu \mathrm{M}$ Oxo-M in the presence of 100, 300 or $500 \mu \mathrm{M}$ ROSC. Calibration: 20 pA, 1 s. (i) Quantification of data revealed ROSC significantly inhibited the Oxo-M-induced suppression of mEPSC frequency in WT mice. Data are presented as the mean \pm S.E.M. ${ }^{*} P<0.05$, ${ }^{\star * P}<0.01$, ${ }^{\star \star *} P<0.001$ vs. vehicle; $\# P<0.05$, \#\#P<0.01, \#\#\#P<0.001 vs. Oxo-M.

\section{Supplementary Files}

This is a list of supplementary files associated with this preprint. Click to download.

- Additionalfile.docx 